Supporting Information for:

\title{
Dynamic kinetic resolution of 3-aryl-4-pentenoic acids
}

\author{
Dominik Koszelewski, Anna Brodzka, Anna Żądło, Daniel Paprocki, Damian Trzepizur, Małgorzata \\ Zysk and Ryszard Ostaszewski \\ Institute of Organic Chemistry PAS, Kasprzaka 44/52, 01-224 Warszawa, Poland \\ *ryszard.ostaszewski@icho.edu.pl
}

Table of contents:

1. General remarks

2. General procedures for the chemo and enzymatic synthesis of compounds $1 \mathrm{a}-\mathrm{g}$ and 2 a-g and racemization procedure of acid $(S)-1 a$ and ester $(S)-2 a$.

3. ${ }^{1} \mathrm{H}$ NMR and ${ }^{13} \mathrm{C}$ NMR spectra of $1 \mathrm{a}-\mathrm{g}$ and 2-a-g.

4. HPLC traces

5. Photographs of rhodium complexes in $\mathrm{CDCl}_{3}$ with NMR spectra

6. Isotopic exchange experiments with isotopic pattern of acid 1a

7. References

\section{General experimental details and materials}

All the chemicals were obtained from commercial sources. The solvents were of analytical grade. Novozym 435 was purchased from Novo Nordisk. NMR spectra were recorded in $\mathrm{CDCl}_{3}$ with $\mathrm{TMS}$ as an internal standard using 200 and $400 \mathrm{MHz}$ spectrometers. The chemical shifts are reported in ppm ( $\delta$ scale) and the coupling constants $(\mathcal{J})$ are given in hertz $(\mathrm{Hz})$. The HPLC analyses were performed on Chiralcel OD-H, Chiralcel AD-H chiral columns. $\varnothing$ $4.6 \mathrm{~mm} \times 250 \mathrm{~mm}$, from Diacel Chemical Ind., Ltd) and Chiralcel OJ chiral columns. $\varnothing 4.6 \mathrm{~mm} \times 250 \mathrm{~mm}$, from Diacel Chemical Ind., Ltd) equipped with a pre-column $(\varnothing 4 \mathrm{~mm} \times 10 \mathrm{~mm}, 5 \mu \mathrm{m})$ using an LC-6A Varian ProStar apparatus with UV Varian ProStar 330 detector and Chromatopac C-R6A analyser. The mobile phase was hexane/isopropanol and the flow rate $1 \mathrm{~mL} / \mathrm{min}, \lambda=254 \mathrm{~nm}$. Melting points are uncorrected. Optical rotations were measured in 1-dm cell of $1 \mathrm{~mL}$ capacity using Jasco DIP-360 polarimeter operating at $589 \mathrm{~nm}$. The elemental analyses were performed on CHN Perkin-Elmer 240 apparatus. All the reactions were monitored by TLC on Merck silica gel Plates $60 \mathrm{~F}_{254}$. Column chromatography was performed on Merck silica gel 60/230-400 mesh. Enzymatic reactions were performed in a vortex mixture (Heidolph Promax 1020) equipped with incubator 
(Heidolph Inkubator 1000). Enantiomeric excess of esters $\mathbf{2 e}$ and $\mathbf{2 f}$ was determined after their hydrolysis to corresponding acids $\mathbf{1 e}$ and $\mathbf{1 f}$ (more details are provided in experimental part).

\section{General procedure for the synthesis of acyclic olefinic esters (2a-g) and corresponding acids (1a-g)}

General procedure A. A mixture of corresponding allylic alcohol (10 mmol), triethyl orthoacetate $(100 \mathrm{mmol})$ and propionic acid $(0.1 \mathrm{~mL}, 1.40 \mathrm{mmol})$ was placed in a round-bottomed flask equipped with thermometer, Claisen head and condenser. The solution was heated at $140{ }^{\circ} \mathrm{C}$ with distillation of ethanol. After $3 \mathrm{~h}$ distillation of ethanol slows and another $0.1 \mathrm{~mL}$ portion of propionic acid was added. Additional portions $(0.1 \mathrm{~mL})$ of propionic acid was added again after 3 and $5 \mathrm{~h}$ followed by continued heating for the next 6 hours. After $6 \mathrm{hr}$ the temperature rose to $166{ }^{\circ} \mathrm{C}$ and TLC analysis indicated that no allylic alcohol remained. The mixture was cooled and the excess of triethyl orthoacetate was removed under reduced pressure. The crude ester $\mathbf{2 a}-\mathbf{g}$ was purified by column chromatography on silica gel (hexanes/ethyl acetate).

Genera procedure B. The solution of ethyl 3-(aryl)pent-4-enoate $(\mathbf{2 a}-\mathbf{g})(4 \mathrm{mmol})$ in methanol $(2 \mathrm{~mL})$ was cooled, and a solution of potassium hydroxide $(40 \mathrm{mmol})$ in water $(10 \mathrm{~mL})$ was added. The mixture was stirred for 8 hours at room temperature. The solution was washed with ethyl ether and acidified with concentrated $\mathrm{HCl}$ to $\mathrm{pH} 2$. The acidic solution was extracted with ethyl acetate $(3 \times 20 \mathrm{~mL})$ and combined organic phases were dried over $\mathrm{MgSO}_{4}$, filtered and concentrated under vacuum. The crude acid was purified by column chromatography on silica gel (hexanes/ethyl acetate).

\section{Ethyl rac-3-(phenyl)pent-4-enoate (2a)}

Prepared according to General procedure A with $85 \%$ yield $(1.74 \mathrm{~g})$ as a colourless oil; ${ }^{1} \mathrm{H}$ NMR $(400 \mathrm{MHz}$, $\mathrm{CDCl}_{3}$ ): $\delta 1.16(\mathrm{t}, J=7.2 \mathrm{~Hz}, 3 \mathrm{H}), 2.70(\mathrm{dd}, J=15.0,7.2 \mathrm{~Hz}, 1 \mathrm{H}), 2.74(\mathrm{dd}, J=15.0,8.0 \mathrm{~Hz}, 1 \mathrm{H}), 3.86(\mathrm{q}, J=7.2$ $\mathrm{Hz}, 1 \mathrm{H}), 4.06(\mathrm{q}, J=7.2 \mathrm{~Hz}, 2 \mathrm{H}), 5.04-5.09(\mathrm{~m}, 2 \mathrm{H}), 5.98$ (ddd, $J=17.4,10.2,7.2 \mathrm{~Hz}, 1 \mathrm{H}), 7.17-7.30(\mathrm{~m}, 5 \mathrm{H}) ;{ }^{13} \mathrm{C}$ NMR $\left(100 \mathrm{MHz}, \mathrm{CDCl}_{3}\right): \delta 14.1,40.3,45.6,60.3,114.7,126.6,127.5,128.5,140.2,142.4,171.8$. The ${ }^{1} \mathrm{H}$ and ${ }^{13} \mathrm{C}$ NMR data were in accordance with those reported in the literature. ${ }^{1}$ HPLC: Chiralcel OD-H; hexane/isopropanol $(9: 1), \lambda=232 \mathrm{~nm} ; 1.0 \mathrm{~mL} / \mathrm{min}$, retention time of the racemic compound (in $\min$ ): $\mathrm{t}_{\mathrm{R}}(S)=5.14, \mathrm{t}_{\mathrm{R}}(R)=4.51$.

rac-3-Phenyl-4-pentenoic acid (1a)

Prepared according to General procedure B with $78 \%$ yield $(0.55 \mathrm{~g})$ as a colourless crystals; $\mathrm{mp} 47^{\circ} \mathrm{C}$ (Lit 48 ${ }^{\circ \mathrm{C} 2}$ ); ${ }^{1} \mathrm{H}$ NMR $\left(400 \mathrm{MHz}, \mathrm{CDCl}_{3}\right): \delta 2.74(\mathrm{dd}, J=15.0,7.5 \mathrm{~Hz}, 1 \mathrm{H}), 2.78(\mathrm{dd}, J=15.0,7.8 \mathrm{~Hz}, 1 \mathrm{H}), 3.90(\mathrm{q}, J=7.2$ $\mathrm{Hz}, 1 \mathrm{H}), 5.00-5.18(\mathrm{~m}, 2 \mathrm{H}), 5.90-6.10(\mathrm{~m}, 1 \mathrm{H}), 7.19-7.40(\mathrm{~m}, 5 \mathrm{H}) ;{ }^{13} \mathrm{C}$ NMR $\left(100 \mathrm{MHz}, \mathrm{CDCl}_{3}\right): \delta 40.2,45.5$, 115.3, 127.1, 127.8, 128.9, 140.2, 142.2, 178.3. The ${ }^{1} \mathrm{H}$ and ${ }^{13} \mathrm{C}$ NMR data were in accordance with those reported in the literature. ${ }^{3}$ HPLC: Chiralcel AD-H; hexane/isopropanol $(9: 1), \lambda=232 \mathrm{~nm} ; 0.3 \mathrm{~mL} / \mathrm{min}$, retention time of the racemic compound (in $\min ): \mathrm{t}_{\mathrm{R}}(S)=17.6, \mathrm{t}_{\mathrm{R}}(R)=19.9$.

\section{Ethyl rac-3-(4-methoxyphenyl)pent-4-enoate (2b)}

Prepared according to General procedure A with $82 \%$ yield $(1.92 \mathrm{~g})$ as a colourless oil; ${ }^{1} \mathrm{H} \mathrm{NMR}(400 \mathrm{MHz}$, $\left.\mathrm{CDCl}_{3}\right): \delta 1.17(\mathrm{t}, J=7.2 \mathrm{~Hz}, 3 \mathrm{H}), 2.65(\mathrm{dd}, J=15.0,7.8 \mathrm{~Hz}, 1 \mathrm{H}), 2.73(\mathrm{dd}, J=15.0,7.8 \mathrm{~Hz}, 1 \mathrm{H}), 3.78(\mathrm{~s}, 3 \mathrm{H})$, $3.81(\mathrm{~m}, 1 \mathrm{H}), 4.06(\mathrm{q}, J=7.2 \mathrm{~Hz}, 2 \mathrm{H}), 5.04(\mathrm{dt}, J=17.4,1.2 \mathrm{~Hz}, 1 \mathrm{H}), 5.09(\mathrm{dt}, J=11.1,1.2 \mathrm{~Hz}, 1 \mathrm{H}), 5.99$ (ddd, $J=$ $17.4,11.1,6.9 \mathrm{~Hz}, 1 \mathrm{H}), 6.83(\mathrm{~d}, \mathrm{~J}=8.8 \mathrm{~Hz}, 2 \mathrm{H}), 7.12(\mathrm{~d}, \mathrm{~J}=8.8 \mathrm{~Hz}, 2 \mathrm{H}) ;{ }^{13} \mathrm{C} \mathrm{NMR}\left(100 \mathrm{MHz}, \mathrm{CDCl}_{3}\right): \delta 14.3$, $40.6,45.0,55.3,60.5,114.1,114.6,128.7,134.6,140.8,158.5,172.1 .{ }^{1} \mathrm{H}$ and ${ }^{13} \mathrm{C}$ NMR data were in accordance with those reported in the literature. ${ }^{4}$ HPLC: Chiralcel OJ; hexane/isopropanol $(9: 1), \lambda=232 \mathrm{~nm} ; 1.0 \mathrm{~mL} / \mathrm{min}$, retention time of the racemic compound (in $\min$ ): $\mathrm{t}_{\mathrm{R}}(S)=24.8, \mathrm{t}_{\mathrm{R}}(R)=30.56$.

\section{rac-3-(4-Methoxyphenyl)-4-pentenoic acid (1b)}

Prepared according to General procedure B with $76 \%$ yield $(0.63 \mathrm{~g})$ as a colourless crystals; ${ }^{1} \mathrm{H}$ NMR $(400 \mathrm{MHz}$, $\left.\mathrm{CDCl}_{3}\right): \delta 2.70(\mathrm{dd}, J=15.6,7.4 \mathrm{~Hz}, 1 \mathrm{H}), 2.78(\mathrm{dd}, J=15.6,8.0 \mathrm{~Hz}, 1 \mathrm{H}), 3.79(\mathrm{~s}, 3 \mathrm{H}), 3.80(\mathrm{~m}, 1 \mathrm{H}), 5.05(\mathrm{dt}, J=$ 17.4, $1.2 \mathrm{~Hz}, 1 \mathrm{H}$ ), 5.09 (dt, $J=11.1,1.2 \mathrm{~Hz}, 1 \mathrm{H}), 5.96$ (ddd, $J=17.4,11.1,6.6 \mathrm{~Hz}, 1 \mathrm{H}), 6.85(\mathrm{~d}, J=8.8 \mathrm{~Hz}, 2 \mathrm{H})$, $7.14(\mathrm{~d}, J=8.8 \mathrm{~Hz}, 2 \mathrm{H}), 10.2(\mathrm{br} s, 1 \mathrm{H}) ;{ }^{13} \mathrm{C}$ NMR $\left(100 \mathrm{MHz}, \mathrm{CDCl}_{3}\right): \delta 40.1,44.3,55.2,114.0,114.6,128.5$, $134.2,140.3,158.4,178.2 .{ }^{1} \mathrm{H}$ and ${ }^{13} \mathrm{C}$ NMR data were in accordance with those reported in the literature.

\section{Ethyl rac-3-(4-methylphenyl)pent-4-enoate (2c)}

Prepared according to General procedure A with $80 \%$ yield $(1.75 \mathrm{~g})$ as a colourless oil; ${ }^{1} \mathrm{HNMR}(400 \mathrm{MHz}$, $\mathrm{CDCl}_{3}$ ): $\delta 1.17(\mathrm{t}, J=7.2 \mathrm{~Hz}, 3 \mathrm{H}), 2.29(\mathrm{~s}, 3 \mathrm{H}), 2.64(\mathrm{dd}, J=15.0,7.6 \mathrm{~Hz}, 1 \mathrm{H}), 2.72(\mathrm{dd}, J=15.0,8.0 \mathrm{~Hz}, 1 \mathrm{H})$, 3.79-3.83 (m, 1H), $4.06(\mathrm{q}, J=7.2 \mathrm{~Hz}, 2 \mathrm{H}), 5.02(\mathrm{dt}, J=17.6,1.2 \mathrm{~Hz}, 1 \mathrm{H}), 5.06(\mathrm{dt}, J=11.3,1.2 \mathrm{~Hz}, 1 \mathrm{H}), 5.94$ (ddd, $J=17.6,11.3,6.9 \mathrm{~Hz}, 1 \mathrm{H}), 7.09(\mathrm{~s}, 4 \mathrm{H}) ;{ }^{13} \mathrm{C}$ NMR $\left(100 \mathrm{MHz}, \mathrm{CDCl}_{3}\right): \delta 14.1,20.9,40.3,45.2,60.3,114.5$, 127.3, 129.2, 136.1, 139.4, 140.4, 171.9. ${ }^{1} \mathrm{H}$ and ${ }^{13} \mathrm{C}$ NMR data were in accordance with those reported in the literature. $^{4}$

\section{rac-3-(4-Methylphenyl)-4-pentenoic acid (1c)}

Prepared according to General procedure B with $76 \%$ yield $(0.58 \mathrm{~g})$ as a colourless crystals; mp $55{ }^{\circ} \mathrm{C}$ (Lit 48 $\left.{ }^{\circ} \mathrm{C}^{5}\right) ;{ }^{1} \mathrm{HNMR}\left(400 \mathrm{MHz}, \mathrm{CDCl}_{3}\right) \delta 2.31(\mathrm{~s}, 3 \mathrm{H}), 2.71(\mathrm{dd}, J=15.5,7.4 \mathrm{~Hz}, 1 \mathrm{H}), 2.76(\mathrm{dd}, J=15.4,7.9 \mathrm{~Hz}, 1 \mathrm{H})$, 3.82 (q, $J=7.2 \mathrm{~Hz}, 1 \mathrm{H}), 5.04-5.08(\mathrm{~m}, 2 \mathrm{H}), 5.95$ (ddd, $J=17.1,10.0,6.9 \mathrm{~Hz}, 1 \mathrm{H}), 7.08(\mathrm{~d}, J=8.8 \mathrm{~Hz}, 2 \mathrm{H}), 7.10$ (d, $J=9.1 \mathrm{~Hz}, 2 \mathrm{H}), 10.83$ (br s, $1 \mathrm{H}) ;{ }^{13} \mathrm{CNMR}\left(100 \mathrm{MHz}, \mathrm{CDCl}_{3}\right) \delta 20.99,39.9,44,7,114.7,127.3,129.3,136.3$, 139.1, 140.1, 177.6. ${ }^{1} \mathrm{H}$ and ${ }^{13} \mathrm{C}$ NMR data were in accordance with those reported in the literature. ${ }^{5}$ 


\section{Ethyl rac-3-(3,4-methylenedioxyphenyl)pent-4-enoate (2d)}

Prepared according to General procedure A with $85 \%$ yield $(2.11 \mathrm{~g})$ as a colourless oil; ${ }^{1} \mathrm{HNMR}(400 \mathrm{MHz}$, $\mathrm{CDCl}_{3}$ ): $\delta 1.18(\mathrm{t}, J=7.2 \mathrm{~Hz}, 3 \mathrm{H}), 2.29(\mathrm{~s}, 3 \mathrm{H}), 2.62(\mathrm{dd}, J=15.0,7.6 \mathrm{~Hz}, 1 \mathrm{H}), 2.70(\mathrm{dd}, J=15.0,8.0 \mathrm{~Hz}, 1 \mathrm{H})$, $3.78(\mathrm{q}, J=8 \mathrm{~Hz}, 1 \mathrm{H}), 4.08(\mathrm{q}, J=7.2 \mathrm{~Hz}, 2 \mathrm{H}), 5.03(\mathrm{dt}, J=17.6,1.2 \mathrm{~Hz}, 1 \mathrm{H}), 5.06(\mathrm{dt}, J=11.3,1.2 \mathrm{~Hz}, 1 \mathrm{H}), 5.91$ $(\mathrm{s}, 2 \mathrm{H}), 5.93$ (ddd, $J=17.6,11.3,6.9 \mathrm{~Hz}, 1 \mathrm{H}), 6.65-6.73(\mathrm{~m}, 3 \mathrm{H}) ;{ }^{13} \mathrm{C} \mathrm{NMR}\left(100 \mathrm{MHz}, \mathrm{CDCl}_{3}\right): \delta 14.1,40.4,45.2$, $60.3,100.8,107.9,108.2,114.5,120.5,136.3,140.3,146.2,147.7,171.7$; Elemental Anal. Calcd. for $\mathrm{C}_{14} \mathrm{H}_{16} \mathrm{O}_{4}: \mathrm{C}$ 67.73, H 6.50; Found: C 67.70, H 6.58.

rac-3-(3,4-methylenedioxyphenyl)-4-pentenoic acid (1d)

Prepared according to General procedure B with $79 \%$ yield $(0.69 \mathrm{~g})$ as a colourless oil; ${ }^{1} \mathrm{HNMR}(400 \mathrm{MHz}$, $\left.\mathrm{CDCl}_{3}\right) \delta 2.70(\mathrm{dd}, J=15.5,7.4 \mathrm{~Hz}, 1 \mathrm{H}), 2.75(\mathrm{dd}, J=15.4,7.9 \mathrm{~Hz}, 1 \mathrm{H}), 3.78(\mathrm{q}, J=7.2 \mathrm{~Hz}, 1 \mathrm{H}), 5.06(\mathrm{dt}, J=$ 17.6, 1.2 Hz, 1H), 5.08 (dt, $J=11.3,1.2 \mathrm{~Hz}, 1 \mathrm{H}$ ), 5.93 (s, 2H), 5.94 (ddd, $J=17.6,11.3,6.9 \mathrm{~Hz}, 1 \mathrm{H}$ ), 6.66-6.75 $(\mathrm{m}, 3 \mathrm{H}) ;{ }^{13} \mathrm{C}$ NMR $\left(100 \mathrm{MHz}, \mathrm{CDCl}_{3}\right): \delta 40.0,44.8,100.9,107.9,108.3,114.8,120.5,135.9,140.1,146.3,147.7$, 177.7; HRMS (El): Calcd. for $\mathrm{C}_{12} \mathrm{H}_{12} \mathrm{O}_{4}[\mathrm{M}]^{++}$, 220.0736, Found 220.0744; HRMS (ESI): Calcd. for $\mathrm{C}_{12} \mathrm{H}_{11} \mathrm{O}_{4}[\mathrm{M}-\mathrm{H}]^{-}$ , 219.0652, Found 219.0657

\section{Ethyl rac-3-(4-chlorophenyl)pent-4-enoate (2e)}

Prepared according to General procedure A with $74 \%$ yield $(1.76 \mathrm{~g})$ as a colourless oil; ${ }^{1} \mathrm{HNMR}(400 \mathrm{MHz}$, $\left.\mathrm{CDCl}_{3}\right): \delta 1.15(\mathrm{t}, J=7.2 \mathrm{~Hz}, 3 \mathrm{H}), 2.63(\mathrm{dd}, J=15.3 \mathrm{~Hz}, 7.8 \mathrm{~Hz}, 1 \mathrm{H}), 2.72(\mathrm{dd}, J=15.3 \mathrm{~Hz}, 7.8 \mathrm{~Hz}, 1 \mathrm{H}), 3.83(\mathrm{q}, J$ $=7.2 \mathrm{~Hz}, 1 \mathrm{H}), 4.07(\mathrm{q}, J=7.2 \mathrm{~Hz}), 5.03(\mathrm{dt}, J=17.1 \mathrm{~Hz}, 1.2 \mathrm{~Hz}, 1 \mathrm{H}), 5.09(\mathrm{dt}, J=10.5 \mathrm{~Hz}, 1.2 \mathrm{~Hz}, 1 \mathrm{H}), 5.94$ (ddd, $J=17.1 \mathrm{~Hz}, 10.5 \mathrm{~Hz}, 6.6 \mathrm{~Hz} ; 1 \mathrm{H}), 7.15(\mathrm{~d}, J=8.4 \mathrm{~Hz}, 2 \mathrm{H}), 7.25(\mathrm{~d}, J=8.4 \mathrm{~Hz}, 2 \mathrm{H}) ;{ }^{13} \mathrm{C} \mathrm{NMR}(100 \mathrm{MHz}$, $\left.\mathrm{CDCl}_{3}\right): \delta 14.4,40.3,45.1,60.7,115.4,128.9,129.2,132.6,140.0,141.1,171.8 .{ }^{1} \mathrm{H}$ and ${ }^{13} \mathrm{C}$ NMR data were in accordance with those reported in the literature. ${ }^{4}$

\section{rac-3-(4-chlorophenyl)-4-pentenoic acid (1e)}

Prepared according to General procedure B with $79 \%$ yield $(0.66 \mathrm{~g})$ as a colourless crystals; mp $57-58{ }^{\circ} \mathrm{C}$ (Lit $\left.55-60{ }^{\circ} \mathrm{C}^{6}\right) ;{ }^{1} \mathrm{HNMR}\left(400 \mathrm{MHz}, \mathrm{CDCl}_{3}\right) \delta 2.69(\mathrm{dd}, J=15.7,7.7 \mathrm{~Hz}, 1 \mathrm{H}), 2.78(\mathrm{dd}, J=15.7,7.7 \mathrm{~Hz}, 1 \mathrm{H}), 3.84(\mathrm{q}, J$ $=7.5 \mathrm{~Hz}, 1 \mathrm{H}), 5.04-5.12(\mathrm{~m}, 2 \mathrm{H}), 5.94$ (ddd, $J=17.1,10.4,6.8 \mathrm{~Hz}, 1 \mathrm{H}), 7.14(\mathrm{~d}, J=8.5 \mathrm{~Hz}, 2 \mathrm{H}), 7.27(\mathrm{~d}, J=8.5$ $\mathrm{Hz}, 2 \mathrm{H}), 9.70$ (br s, $1 \mathrm{H}) ;{ }^{13} \mathrm{C}$ NMR $\left(100 \mathrm{MHz} \mathrm{CDCl}_{3}\right): \delta 39.7,44.4,115.4,128.7,128.9,132.6,139.4,140.5$, 177.7. ${ }^{1} \mathrm{H}$ and ${ }^{13} \mathrm{C}$ NMR data were in accordance with those reported in the literature. ${ }^{5} \mathrm{HPLC}$ : Chiralcel AD-H; hexane/isopropanol (9:1), $\lambda=232 \mathrm{~nm} ; 0.5 \mathrm{~mL} / \mathrm{min}$, retention time of the racemic compound (in $\min$ ): $t_{R}(S)=12.0$, $\mathrm{t}_{\mathrm{R}}(R)=13.9$.

\section{Ethyl rac-3-(4-fluorophenyl)pent-4-enoate (2f) \\ Prepared according to General procedure A with $87 \%$ yield $(1.93 \mathrm{~g})$ as a colourless oil; ${ }^{1} \mathrm{HNMR}(400 \mathrm{MHz}$, $\left.\mathrm{CDCl}_{3}\right): \delta 1.15(\mathrm{t}, J=7.2 \mathrm{~Hz}, 3 \mathrm{H}), 2.63(\mathrm{dd}, J=15.3 \mathrm{~Hz}, 7.8 \mathrm{~Hz}, 1 \mathrm{H}), 2.72(\mathrm{dd}, J=15.3 \mathrm{~Hz}, 7.8 \mathrm{~Hz}, 1 \mathrm{H}), 3.83(\mathrm{q}, J$ $=7.2 \mathrm{~Hz}, 1 \mathrm{H}), 4.07(\mathrm{q}, J=7.2 \mathrm{~Hz}), 5.01(\mathrm{dt}, J=17.1 \mathrm{~Hz}, 1.2 \mathrm{~Hz}, 1 \mathrm{H}), 5.07(\mathrm{dt}, J=10.5 \mathrm{~Hz}, 1.2 \mathrm{~Hz}, 1 \mathrm{H}), 5.94$ (ddd, $J=17.1 \mathrm{~Hz}, 10.5 \mathrm{~Hz}, 6.6 \mathrm{~Hz} ; 1 \mathrm{H}), 6.94-6.98(\mathrm{~m}, 2 \mathrm{H}), 7.13-7.18(\mathrm{~m}, 2 \mathrm{H}) ;{ }^{13} \mathrm{C} \mathrm{NMR}\left(100 \mathrm{MHz}, \mathrm{CDCl}_{3}\right): \delta$ 14.1, 40.3, 44.8, 60.4, 114.9, 115.2, 115.4, 129.0, 129.1, 140.1, 160.4, 171.6; Elemental Anal. Calcd. for $\mathrm{C}_{13} \mathrm{H}_{16} \mathrm{FO}_{2}$ : C 70.25, H 6.80; Found: C 70.10, H 6.80; HRMS (El): Calcd. for $\mathrm{C}_{13} \mathrm{H}_{12} \mathrm{FO}_{2}[\mathrm{M}]^{\circ+}$, 222.1056, Found 222.1055;}

\section{rac-3-(4-fluorophenyl)-4-pentenoic acid (1f)}

Prepared according to General procedure B with $71 \%$ yield $(0.55 \mathrm{~g})$ as a colourless crystals; mp $59-60{ }^{\circ} \mathrm{C}$ (Lit $\left.58-60{ }^{\circ} \mathrm{C}^{5}\right) ;{ }^{1} \mathrm{HNMR}\left(400 \mathrm{MHz}, \mathrm{CDCl}_{3}\right) \delta 2.67(\mathrm{dd}, J=15.6,7.6 \mathrm{~Hz}, 1 \mathrm{H}), 2.77(\mathrm{dd}, J=15.7,7.6 \mathrm{~Hz}, 1 \mathrm{H}), 3.83(\mathrm{q}, J$ $=7.6 \mathrm{~Hz}, 1 \mathrm{H}), 5.02-5.09(\mathrm{~m}, 2 \mathrm{H}), 5.94(\mathrm{ddd}, J=17.1,10.4,6.7 \mathrm{~Hz}, 1 \mathrm{H}), 6.94-6.99(\mathrm{~m}, 2 \mathrm{H}), 7.00-7.14(\mathrm{~m}, 2 \mathrm{H}) ;{ }^{13} \mathrm{C}$ $\operatorname{NMR}\left(100 \mathrm{MHz}, \mathrm{CDCl}_{3}\right): \delta 39.9,44.3,115.1,115.3,115.5,128.9,129.0,137.7,137.7,139.4,160.4,162.9,177.5$. ${ }^{1} \mathrm{H}$ and ${ }^{13} \mathrm{C}$ NMR data were in accordance with those reported in the literature. ${ }^{5}$ LRMS (ESI): Calcd. for $\mathrm{C}_{11} \mathrm{H}_{10} \mathrm{FO}_{2}[\mathrm{M}-\mathrm{H}]$ ], 193.06, Found 193.02. HPLC: Chiralcel AD-H; hexane/isopropanol/AcOH (9:1:0.05), $\lambda=232$ $\mathrm{nm} ; 0.8 \mathrm{~mL} / \mathrm{min}$, retention time of the racemic compound (in $\min$ ): $\mathrm{t}_{\mathrm{R}}(S)=6.5, \mathrm{t}_{\mathrm{R}}(R)=7.4$.

\section{Ethyl rac-3-(4-nitrophenyl)pent-4-enoate (2g)}

Prepared according to general procedure A with $69 \%$ yield $(1.72 \mathrm{~g})$ as a light yellow oil; ${ }^{1} \mathrm{H} \mathrm{NMR}(400 \mathrm{MHz}$, $\left.\mathrm{CDCl}_{3}\right): \delta 1.16(\mathrm{t}, J=7.2 \mathrm{~Hz}, 3 \mathrm{H}), 2.71(\mathrm{dd}, J=7.6,15.4 \mathrm{~Hz}, 1 \mathrm{H}), 2.81(\mathrm{dd}, J=7.6,15.4 \mathrm{~Hz}, 1 \mathrm{H}), 3.90-3.95(\mathrm{~m}$, $1 \mathrm{H}$ ), $4.06(\mathrm{q}, J=7.2 \mathrm{~Hz}, 2 \mathrm{H}), 5.11(\mathrm{~d}, J=17.4 \mathrm{~Hz}, 1 \mathrm{H}), 5.15(\mathrm{~d}, J=10.3 \mathrm{~Hz}, 1 \mathrm{H}$ ), 5.92 (ddd, $J=8.6,10.3,17.2$ $\mathrm{Hz}, 1 \mathrm{H}), 7.38(\mathrm{~d}, J=8.9 \mathrm{~Hz}, 2 \mathrm{H}), 8.16(\mathrm{~d}, J=8.9 \mathrm{~Hz}, 2 \mathrm{H}) ;{ }^{13} \mathrm{C} \mathrm{NMR}\left(100 \mathrm{MHz}, \mathrm{CDCl}_{3}\right): \delta$ 14.1, 39.7.6, 45.2, 60.6, $116.1,123.8,128.5,138.7,146.8,150.0,171.0 .{ }^{1} \mathrm{H}$ and ${ }^{13} \mathrm{C}$ NMR data were in accordance with those reported in the literature. ${ }^{7}$ Chiralcel $A D-H$; hexane/isopropanol/AcOH $(95: 5), \lambda=232 \mathrm{~nm} ; 0.5 \mathrm{~mL} / \mathrm{min}$, retention time of the racemic compound (in $\min$ ): $\mathrm{t}_{R}=17.0, \mathrm{t}_{R}=18.6$.

rac-3-(4-Nitrohenyl)-4-pentenoic acid (1g)

Prepared according to general procedure B with $81 \%$ yield $(0.72 \mathrm{~g})$ as a light yellow crystals; ${ }^{1} \mathrm{H} \mathrm{NMR}(400 \mathrm{MHz}$, $\left.\mathrm{CDCl}_{3}\right): \delta 2.75(\mathrm{dd}, J=16.0,7.6 \mathrm{~Hz}, 1 \mathrm{H}), 2.84(\mathrm{dd}, J=15.6,7.6 \mathrm{~Hz}, 1 \mathrm{H}), 3.96(\mathrm{q}, J=7.6 \mathrm{~Hz}, 1 \mathrm{H}), 5.08(\mathrm{dt}, J=$ 17.4, 1.2 Hz, $1 \mathrm{H}$, ), $5.16(\mathrm{dt}, J=11.1,1.2 \mathrm{~Hz}, 1 \mathrm{H}), 5.93$ (ddd, $J=17.4,11.1,6.6 \mathrm{~Hz}, 1 \mathrm{H}), 7.37(\mathrm{~d}, J=8.8 \mathrm{~Hz}, 2 \mathrm{H})$, $8.16(\mathrm{~d}, J=8.8 \mathrm{~Hz}, 2 \mathrm{H}) ;{ }^{13} \mathrm{C}$ NMR $\left(100 \mathrm{MHz} \mathrm{CDCl}_{3}\right): \delta 39.3,44.8,116.4,123.9,128.5,138.4,149.6,177.1$; 
Elemental Anal. Calcd. for $\mathrm{C}_{11} \mathrm{H}_{11} \mathrm{NO}_{4}: \mathrm{C} 59.73$, H 5.01, N 6.33; Found: C 59.62, H 5.18, N 6.28; HRMS (ESI): Exact mass calcd. for $\mathrm{C}_{11} \mathrm{H}_{10} \mathrm{NO}_{4}[\mathrm{M}-\mathrm{H}]$;, 220.0610, Found 220.0615 .

\section{General procedure for enzymatic kinetic resolution.}

To the solution of acid 1a-g $(0.2 \mathrm{mmol})$ in toluene $(5 \mathrm{~mL})$, triethyl orthobenzoate or other alkoxy group donor (3 equiv.) and enzyme (10 mg) were added in $10 \mathrm{~mL}$ screwed vial. The reaction mixture was stirred for 72 hours at $60{ }^{\circ} \mathrm{C}$. After cooling, crude product was purified by column chromatography (ethyl acetate/hexanes) (yield of 2a-g are given in Table 2 in main Text). The ${ }^{1} \mathrm{H}$ NMR data were in accordance with those recorded for racemates. The ${ }^{1} \mathrm{H}$ NMR data were in accordance with those recorded for racemates; $(S)-(-)-2 \mathbf{a}:[\alpha]_{D}^{20}=-9.2$ (c $0.8 \mathrm{CHCl}_{3},>99 \%$ $e e)$, to determine absolute configuration ester $(S)-(-)-2 \mathbf{a}$ was hydrolyzed to acid $(S)-(-)-1 \mathbf{a}:\left([\alpha]_{D}^{20}=-18.7\right.$ (c 1.0 $\mathrm{CHCl}_{3}$ ) Lit $(R)$-1a enantiomer: $[\alpha]_{D}^{20} .=+18.6\left(\mathrm{c} 1.1, \mathrm{CHCl}_{3}\right){ }^{5}(S)-(-)-2 \mathbf{b}:[\alpha]_{D}^{20}=-5.7$ (c $1.00 \mathrm{CHCl}_{3}, 48 \%$ ee), to determine absolute configuration ester (S)-(-)-2b was hydrolyzed to acid (S)-(-)-1b: $\left([\alpha]_{D}^{20}=-8.2\right.$ (c $\left.1.0 \mathrm{CHCl}_{3}\right) \mathrm{Lit}^{2}$ $(R)-(+)$-1b enantiomer: $[\alpha]_{D}^{20} .=+20.0$ (c 2.0, $\mathrm{CHCl}_{3},>99 \%$ ee) $;^{5}(S)-(-)-2 \mathrm{e}:[\alpha]_{D}^{20}=-11.8$ (c $\left.0.90, \mathrm{CHCl}_{3}, 92 \% e e\right)$, to determine absolute configuration ester $(S)-(-)-2 e$ was hydrolyzed to acid $(S)-(-)-1 e:\left([\alpha]_{D}^{20}=-15.6(c 1.0, \mathrm{PhH})\right.$ Lit $(S)-(-)-1 e$ enantiomer: $[\alpha]_{D}^{20} .=-14.4$ (c 1.39, $\mathrm{PhH}, 94 \%$ ee) $;^{6} .{ }^{6}$ (S)-(-)-2f: $[\alpha]_{D}^{20}=-21.8$ (c 1.00, $\mathrm{CHCl}_{3}, 97 \%$ ee), to determine absolute configuration ester $(S)-(-)-2 f$ was hydrolyzed to acid $(S)-(-)-\mathbf{1 f}:\left([\alpha]_{D}^{20}=-26.2\left(\mathrm{c} 1.0, \mathrm{CHCl}_{3}\right)\right.$ Lit $(R)-(+)-1 f$ enantiomer: $[\alpha]_{D}^{20} .=+21.0\left(\right.$ c $2.00, \mathrm{CHCl}_{3},>90.5 \%$ ee $) ;^{5}(-)-\mathbf{2 g}$ : $[\alpha]_{D}^{20}=-0.7$ (c $1.00, \mathrm{CHCl}_{3}, 16 \%$ ee), Lit $(+)-2 \mathrm{~g}:[\alpha]_{D}^{20} .=+1.5\left(\mathrm{c} 0.85, \mathrm{CHCl}_{3}, 99 \%\right.$ ee $) ;^{7}$

\section{General procedure for dynamic enzymatic kinetic resolution}

To the solution of acid $\mathbf{1 a , b}$ or $\mathbf{1 e - g}(0.2 \mathrm{mmol})$ in toluene $(5 \mathrm{~mL})$, triethyl orthobenzoate (3 equiv.), enzyme (10 $\mathrm{mg}$ ) and metal catalyst (10 mol\%) were added in $10 \mathrm{~mL}$ vial. The reaction mixture was stirring for 120 hours at 60 ${ }^{\circ} \mathrm{C}$. After cooling, crude product was purified by column chromatography (ethyl acetate/hexanes). The ${ }^{1} \mathrm{H}$ NMR data were in accordance with those recorded for racemates; $(S)-(-)-2 \mathbf{a}:[\alpha]_{D}^{20}=-9.31$ (c $1.0 \mathrm{CHCl}_{3},>99 \%$ ee); (S)-()-2b: $[\alpha]_{D}^{20}=-4.8$ (c $0.9 \mathrm{CHCl}_{3}, 43 \%$ ee); (S)-(-)-2e: $[\alpha]_{D}^{20}=-11.2$ (c 1.0, $\mathrm{CHCl}_{3}, 90 \%$ ee); (S)-(-)-2f: $[\alpha]_{D}^{20}=-20.9$ (c 1.05, $\mathrm{CHCl}_{3}, 95 \%$ ee); (-)-2g: $[\alpha]_{D}^{20}=-0.4$ (c $1.00, \mathrm{CHCl}_{3}, 10 \%$ ee) .

\section{Racemization of (S)-3-phenyl-4-pentenoic acid ((S)-1a)}

To the solution of ester $(S)$-1a $(0.1 \mathrm{mmol})$ in various organic solvent $(3 \mathrm{~mL})$ were added (see Table 1 in main Text); transition metal catalyst (10 mol\%) and base (if necessary, $4 \mathrm{~mol} \%$ ) were added in $5 \mathrm{~mL}$ vial. The reaction mixture was stirred for 24 hours at various temperatures in vortex mixture (HeidolphPromax 1020) equipped with incubator (HeidolphInkubator 1000). After cooling, crude product was purified by column chromatography (ethyl acetate/hexanes) and analyzed on HPLC using OD-H column.

\section{Racemization of ethyl (S)-3-(phenyl)pent-4-enoate ((S)-2a)}

To the solution of ester (S)-2a $(0.1 \mathrm{mmol})$ in toluene $(3 \mathrm{~mL})$ rhodium(II) acetate dimer $(10$ mol\%) was added. The reaction mixture was stirred for 24 hours at $60{ }^{\circ} \mathrm{C}$ in vortex mixture (HeidolphPromax 1020) equipped with incubator (Heidolphlnkubator 1000). After cooling, crude product was purified by column chromatography (ethyl acetate/hexanes) and analyzed on HPLC using OD-H column.

\footnotetext{
General procedure for dynamic enzymatic kinetic resolution with enzyme and rhodium(II) acetate recycling

To the solution of acid 1a $(0.2 \mathrm{mmol})$ in toluene $(5 \mathrm{~mL})$, triethyl orthobenzoate (3 equiv.), enzyme (10 mg) and metal catalyst (10 mol\%) were added in $10 \mathrm{~mL}$ vial. The reaction mixture was stirring for 120 hours at $60{ }^{\circ} \mathrm{C}$. Still warm solution was filtered through the schott funnel to separate enzyme followed by enzyme flushing with ethyl acetate $(3 \times 10 \mathrm{~mL})$. Collected organic phase was evaporated under reduced pressure and product was purified by column chromatography (ethyl acetate/hexanes). Catalyst was recovered from the column by washing out with ethyl acetate. Solvent was evaporated and catalyst was recrystallized from methanol. The ${ }^{1} \mathrm{H}$ NMR data of ester $\mathbf{2 a}$ obtained in repeated cycles were in accordance with those recorded for racemates.
}

\section{Synthesis of ethyl (S)-3-(phenyl)pent-4-enoate ((S)-2a) - preparative scale}

To the solution of acid 1a $(176 \mathrm{mg}, 1 \mathrm{mmol})$ in toluene $(10 \mathrm{~mL})$, triethyl orthobenzoate $(673 \mathrm{mg}, 3 \mathrm{mmol})$, Novozym $435(50 \mathrm{mg})$ and rhodium(II) acetate $(10 \mathrm{~mol} \%)$ was stirred for five days at $60{ }^{\circ} \mathrm{C}$ in vortex mixture (Heidolph Promax 1020) equipped with incubator (Heidolph Inkubator 1000). Enzyme and catalyst were separated by filtration and washed with ethyl acetate. Combined organic phases were evaporated in vacuum and purified by column chromatography (ethyl acetate/hexanes). Product (S)-2a was obtained with 97\% yield (198 
$\mathrm{mg})$ as a colourless oil. The ${ }^{1} \mathrm{H}$ NMR data were in accordance with those recorded for racemate; $(S)-(-)-2 \mathrm{a}:[\alpha]_{D}^{20}=$ -9.42 (c $1.0 \mathrm{CHCl}_{3},>99 \%$ ee).

\section{Synthesis of ethyl (S)-3-(4-chlorophenyl)pent-4-enoate ((S)-2e) - preparative scale}

To the solution of acid $1 \mathrm{e}(211 \mathrm{mg}, 1 \mathrm{mmol})$ in toluene $(10 \mathrm{~mL})$, triethyl orthobenzoate $(680 \mathrm{mg}, 3 \mathrm{mmol})$, Novozym $435(53 \mathrm{mg})$ and rhodium(II) acetate $(10 \mathrm{~mol} \%)$ was stirred for five days at $60{ }^{\circ} \mathrm{C}$ in vortex mixture (Heidolph Promax 1020) equipped with incubator (Heidolph Inkubator 1000). Enzyme and catalyst were separated by filtration and washed with ethyl acetate. Combined organic phases were evaporated in vacuum and purified by column chromatography (ethyl acetate/hexanes). Product (S)-2e was obtained with $76 \%$ yield (181 $\mathrm{mg})$ as a colourless oil. The ${ }^{1} \mathrm{H}$ NMR data were in accordance with those recorded for racemate; $(S)-(-)-2 \mathrm{e}:[\alpha]_{D}^{20}=$ -11.4 (c $1.0, \mathrm{CHCl}_{3}, 90 \%$ ee).

\section{Synthesis of ethyl (S)-3-(4-fluorophenyl)pent-4-enoate ((S)-2f) - preparative scale}

To the solution of acid $1 \mathrm{f}(195 \mathrm{mg}, 1 \mathrm{mmol})$ in toluene $(10 \mathrm{~mL})$, triethyl orthobenzoate $(668 \mathrm{mg}, 3 \mathrm{mmol})$, Novozym $435(51 \mathrm{mg})$ and rhodium(II) acetate $(10 \mathrm{~mol} \%)$ was stirred for five days at $60{ }^{\circ} \mathrm{C}$ in vortex mixture (Heidolph Promax 1020) equipped with incubator (Heidolph Inkubator 1000). Enzyme and catalyst were separated by filtration and washed with ethyl acetate. Combined organic phases were evaporated in vacuum and purified by column chromatography (ethyl acetate/hexanes). Product (S)-2f was obtained with $90 \%$ yield $(201 \mathrm{mg})$ as a colourless oil. The ${ }^{1} \mathrm{H}$ NMR data were in accordance with those recorded for racemate; $(S)-(-)-2 \mathrm{f}:[\alpha]_{D}^{20}=-$ 21.3 (c $1.05, \mathrm{CHCl}_{3}, 95 \%$ ee).

\section{3. ${ }^{1} \mathrm{H}$ and ${ }^{13} \mathrm{C}$ NMR spectra for $1 \mathrm{a}-\mathrm{g}$ and $2 \mathrm{a}-\mathrm{g}$ :}

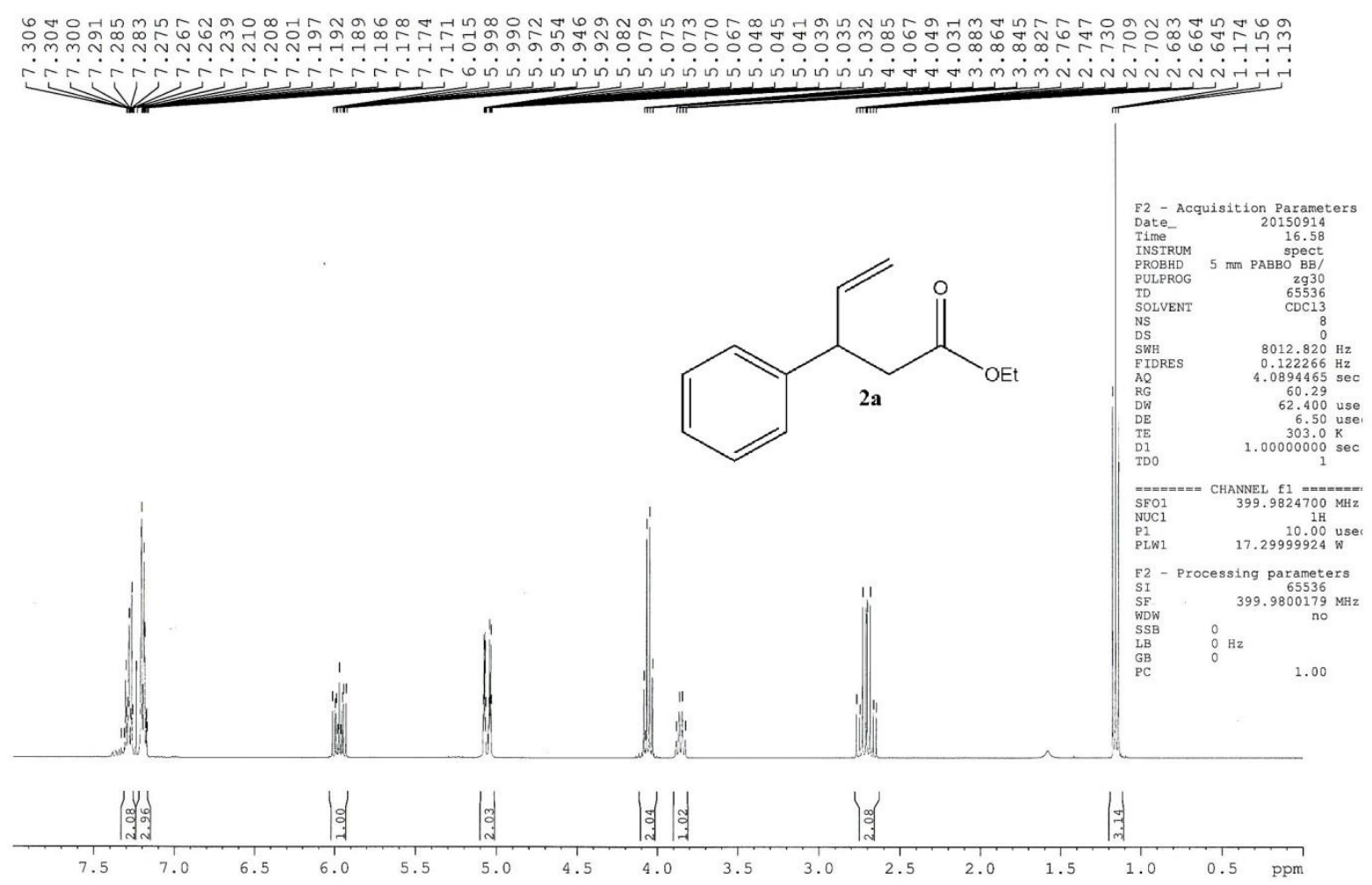




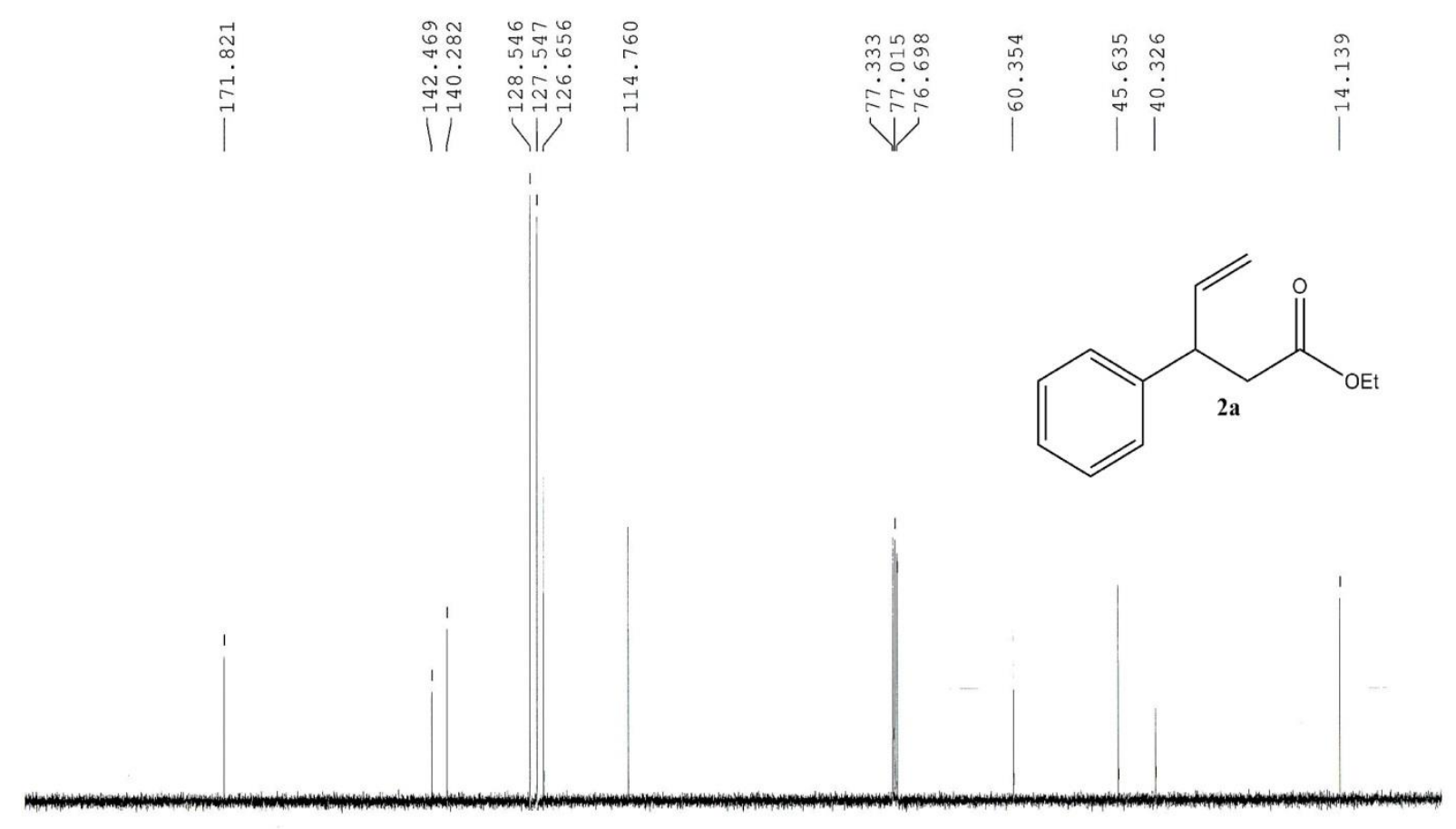

\begin{tabular}{|c|c|c|c|c|c|c|c|c|c|c|c|c|c|c|c|c|c|}
\hline 190 & 180 & 170 & 160 & 150 & 140 & 130 & 120 & 110 & 100 & 90 & 80 & 70 & 60 & 50 & 40 & 30 & 20 \\
\hline
\end{tabular}

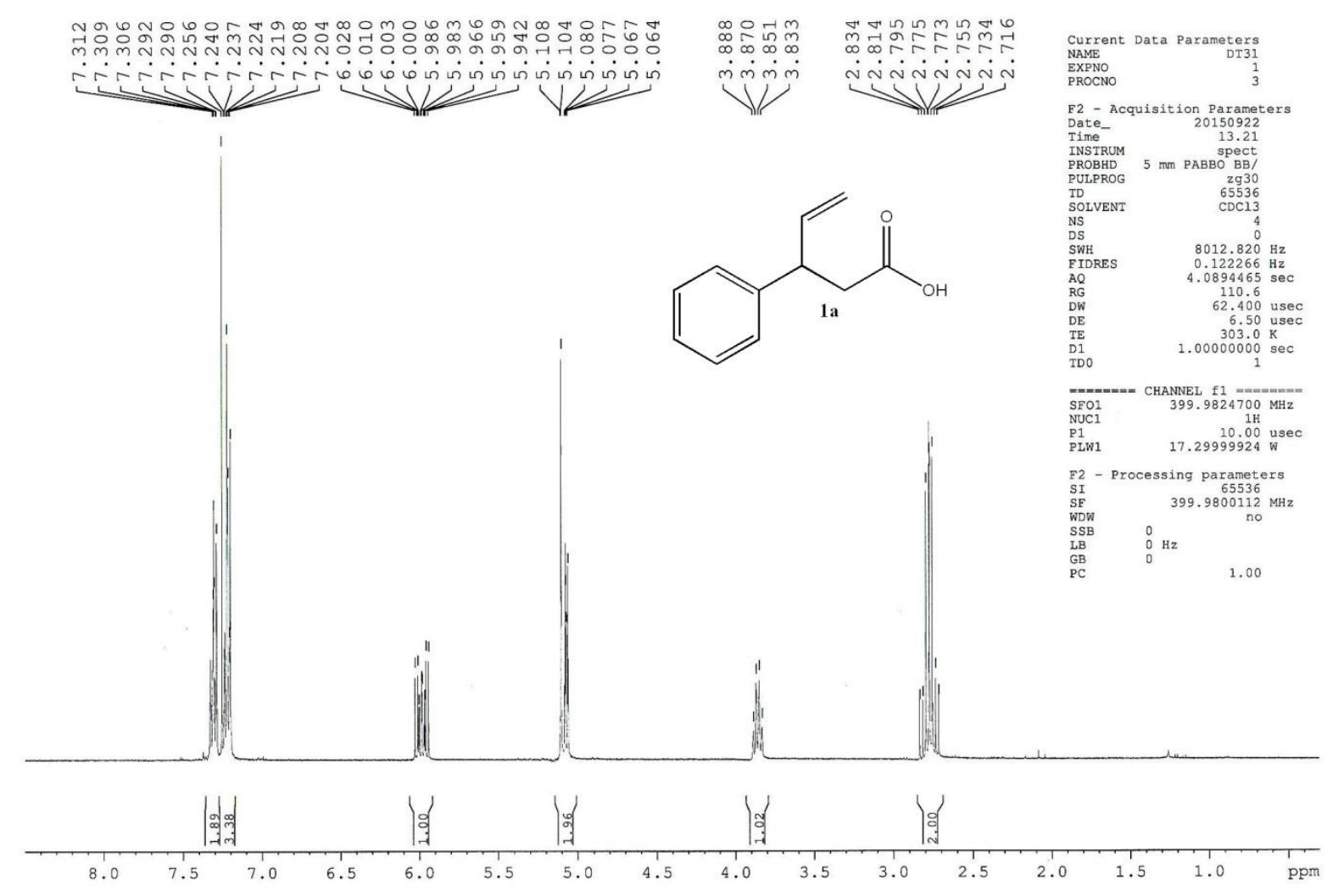




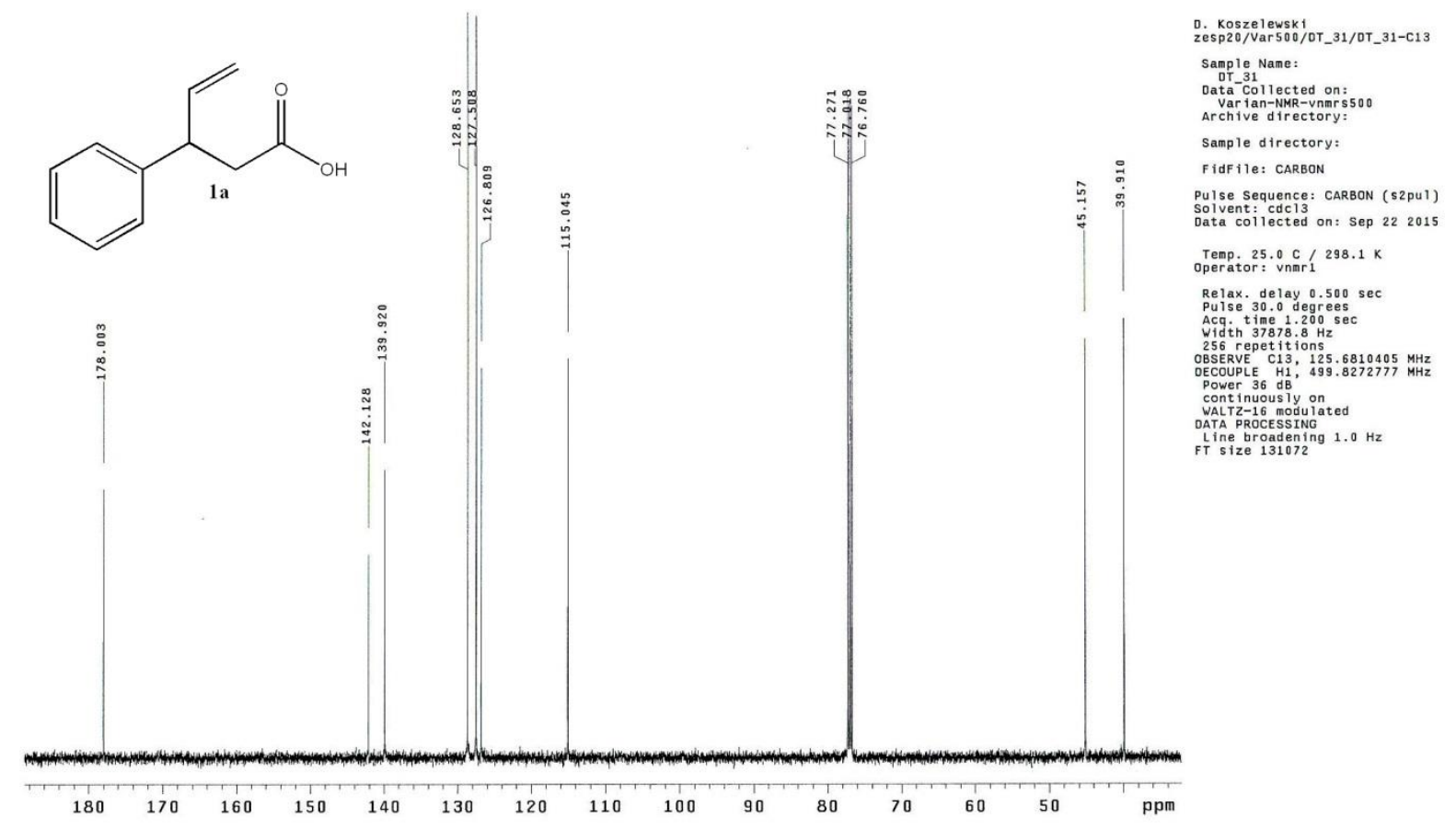

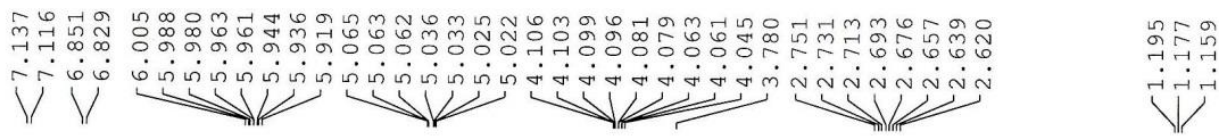

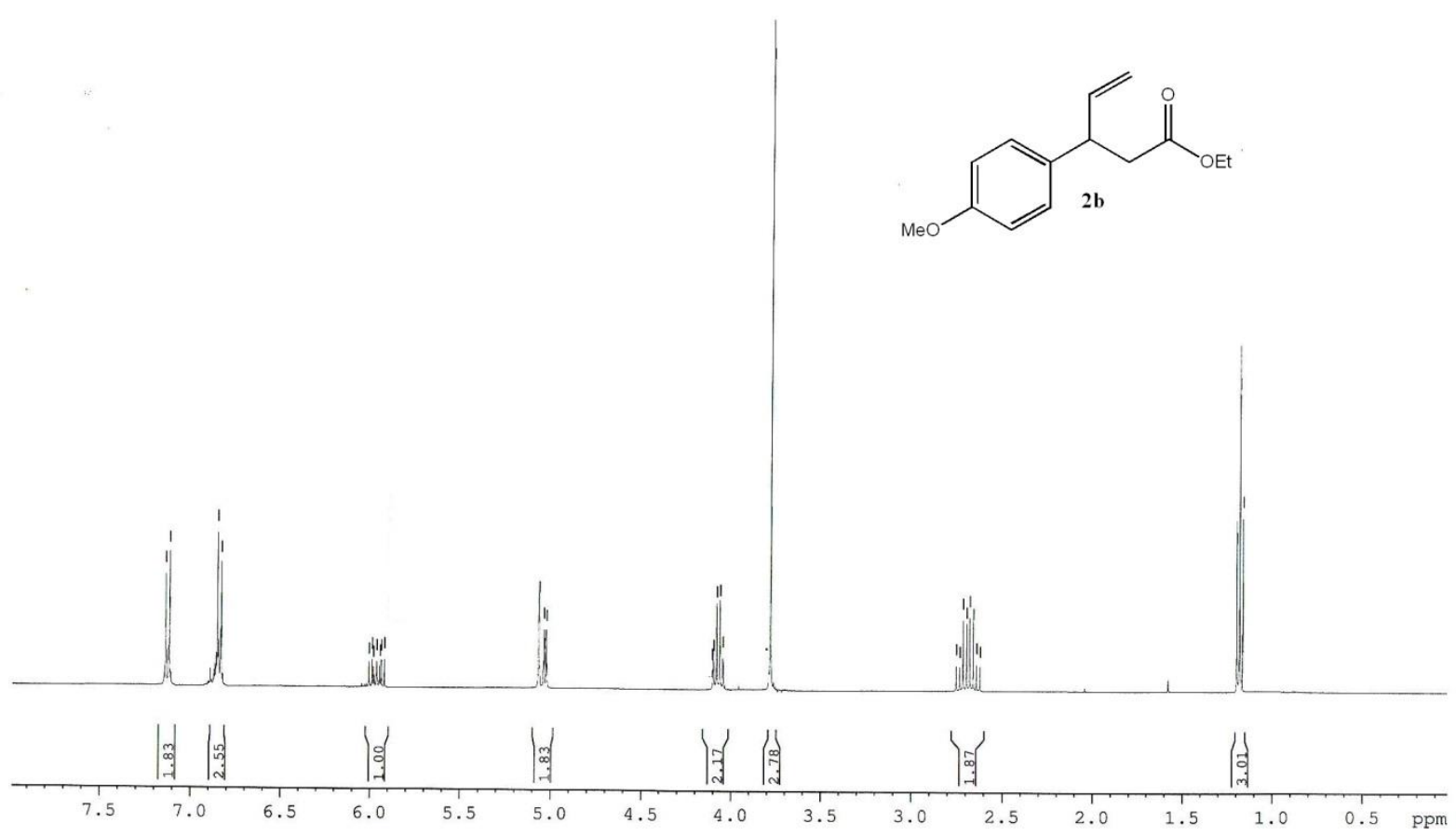




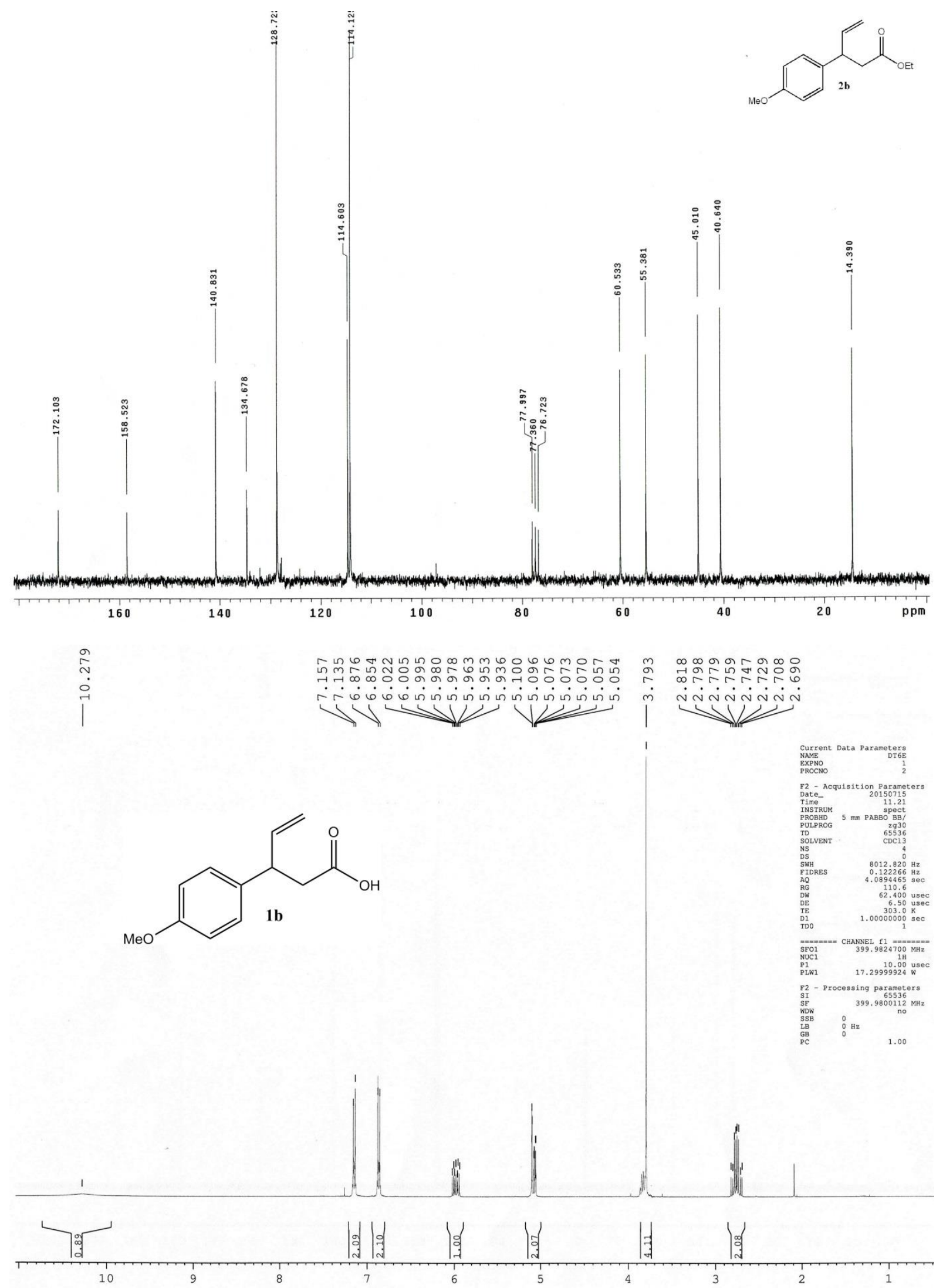




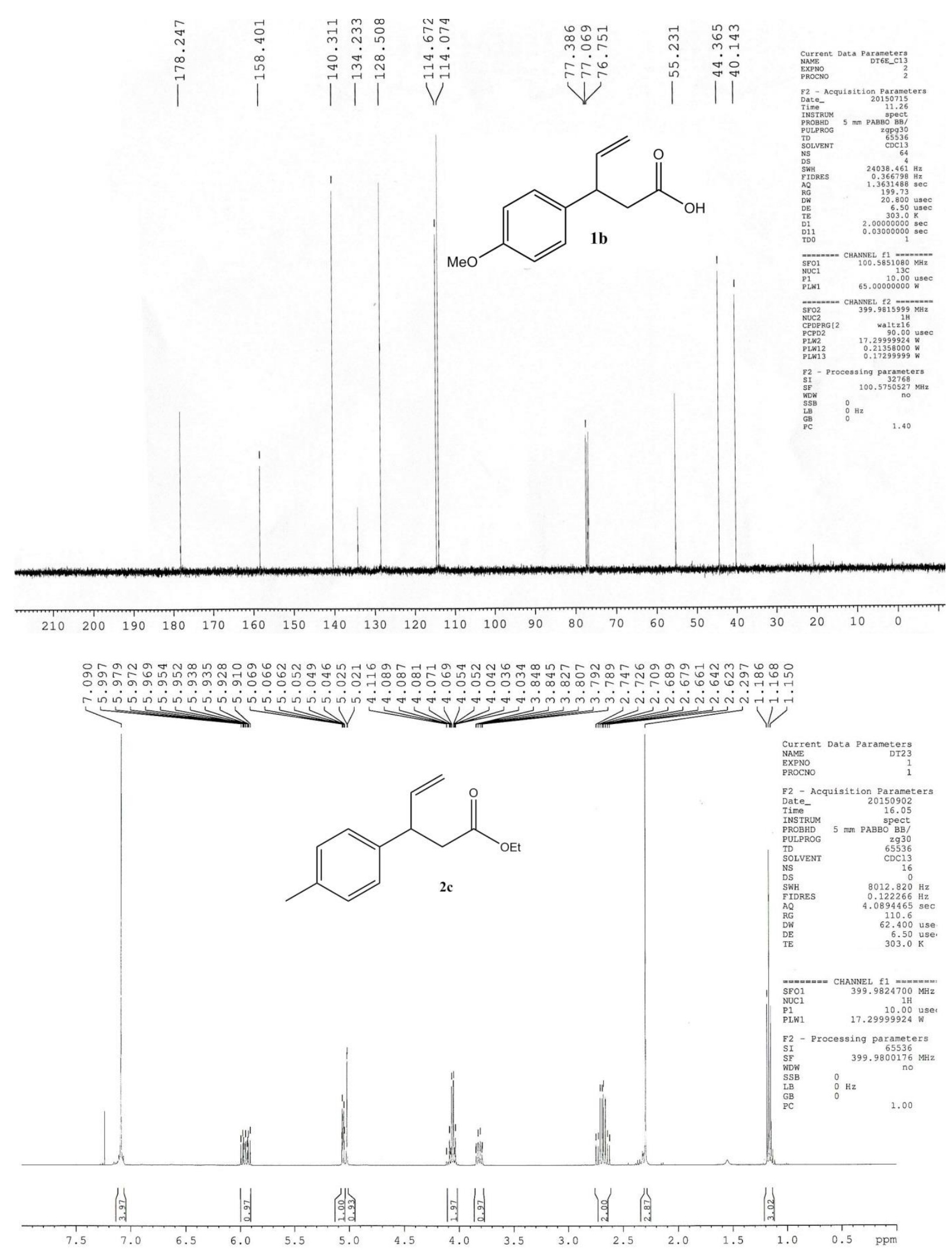



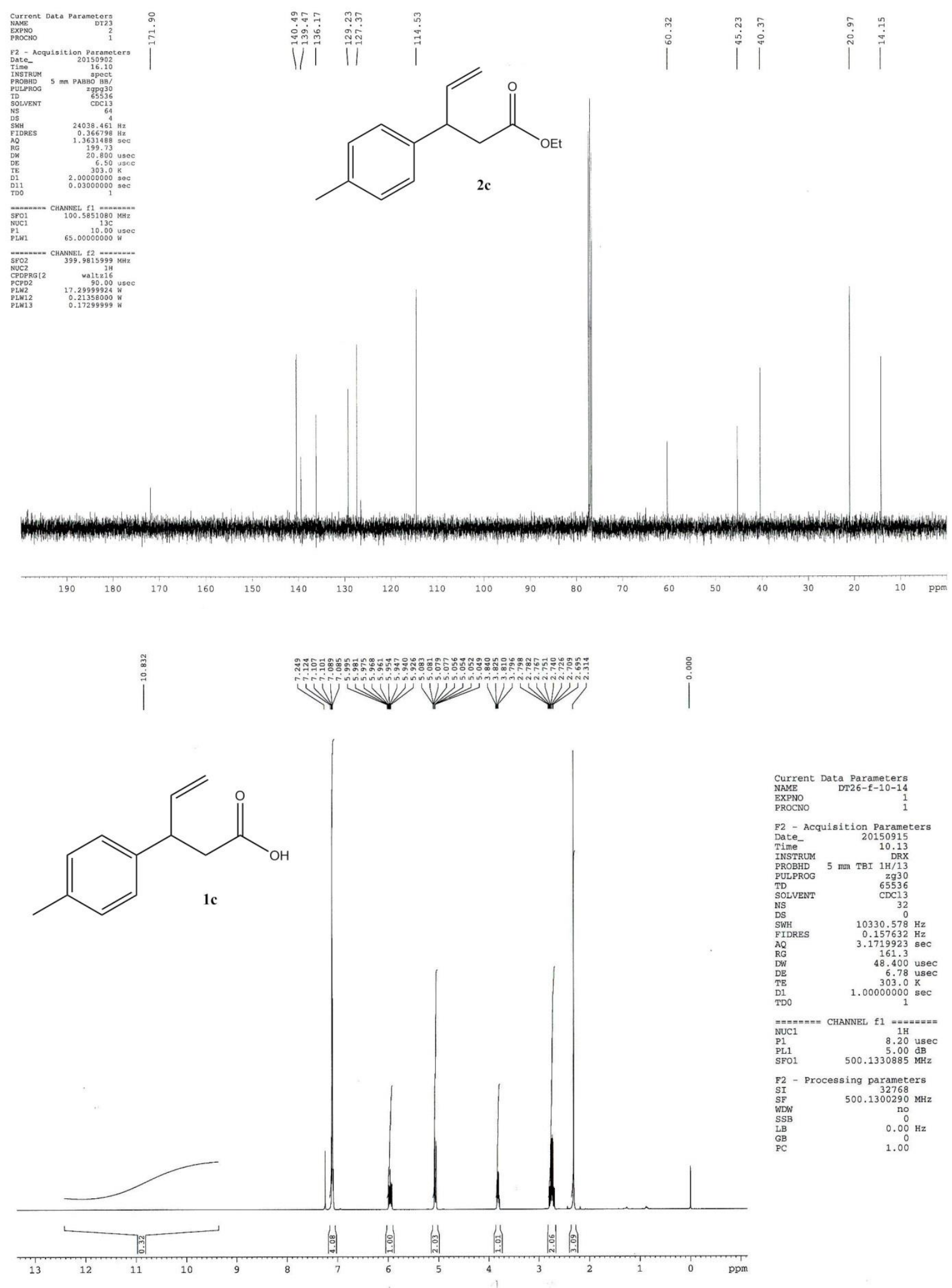


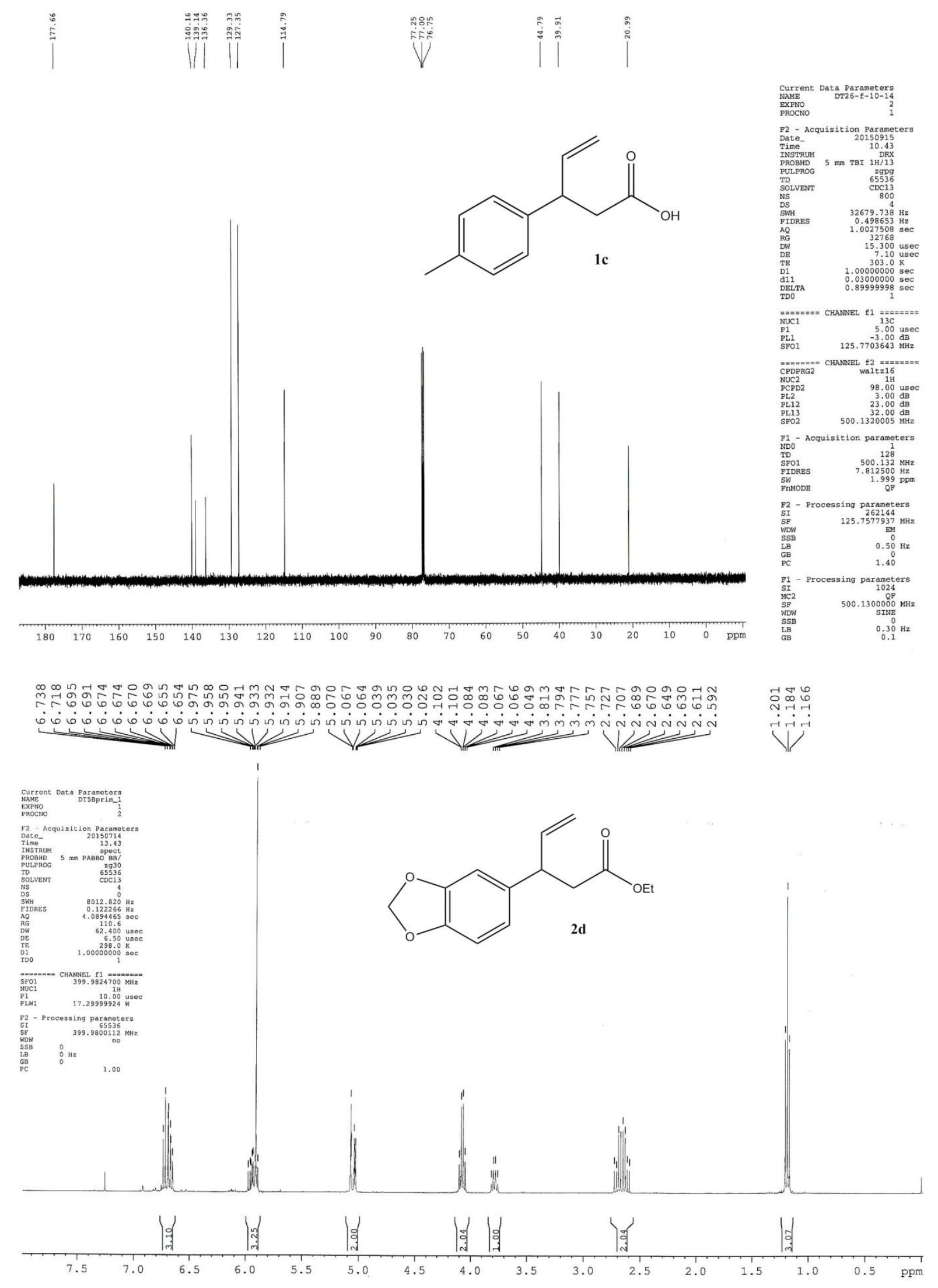



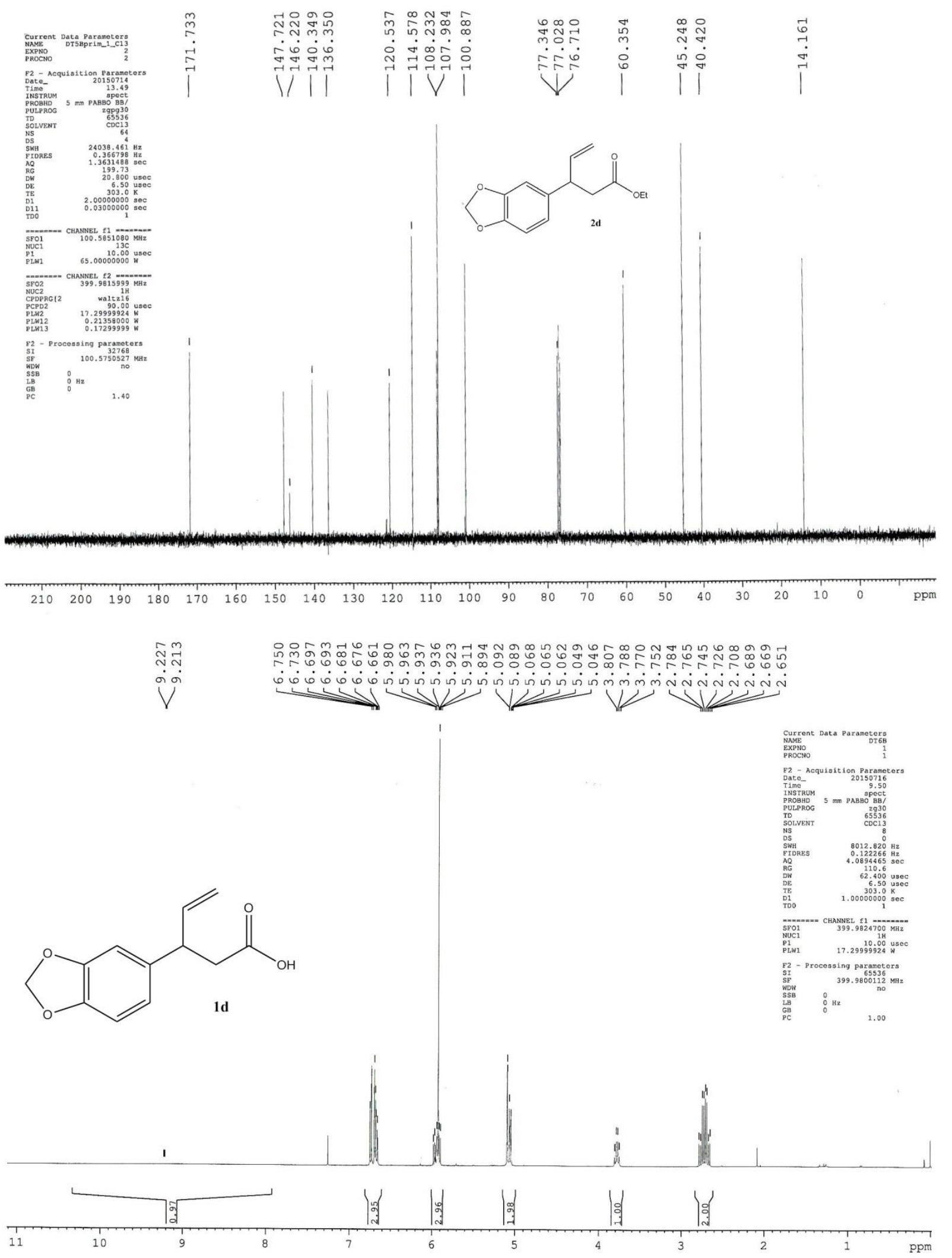

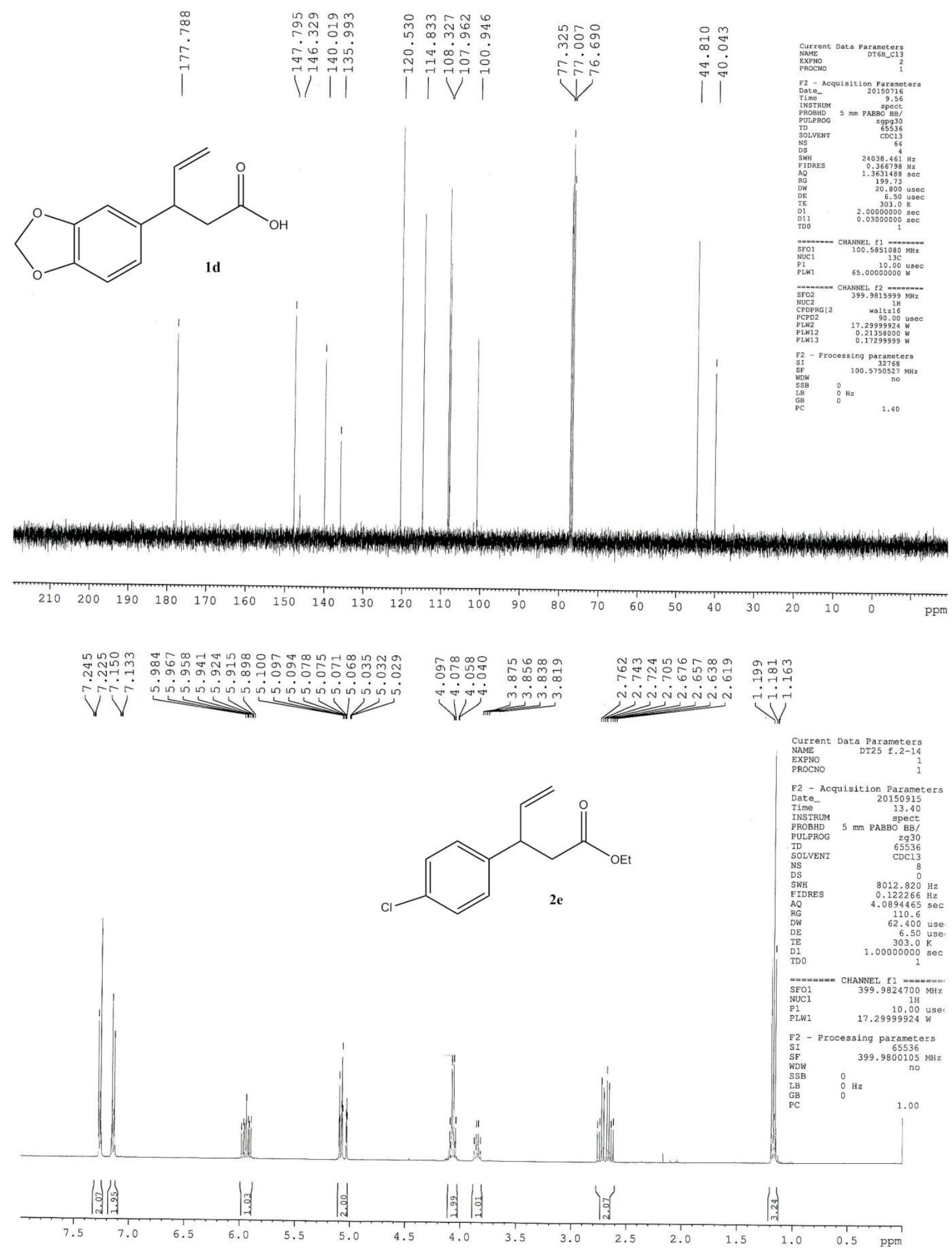


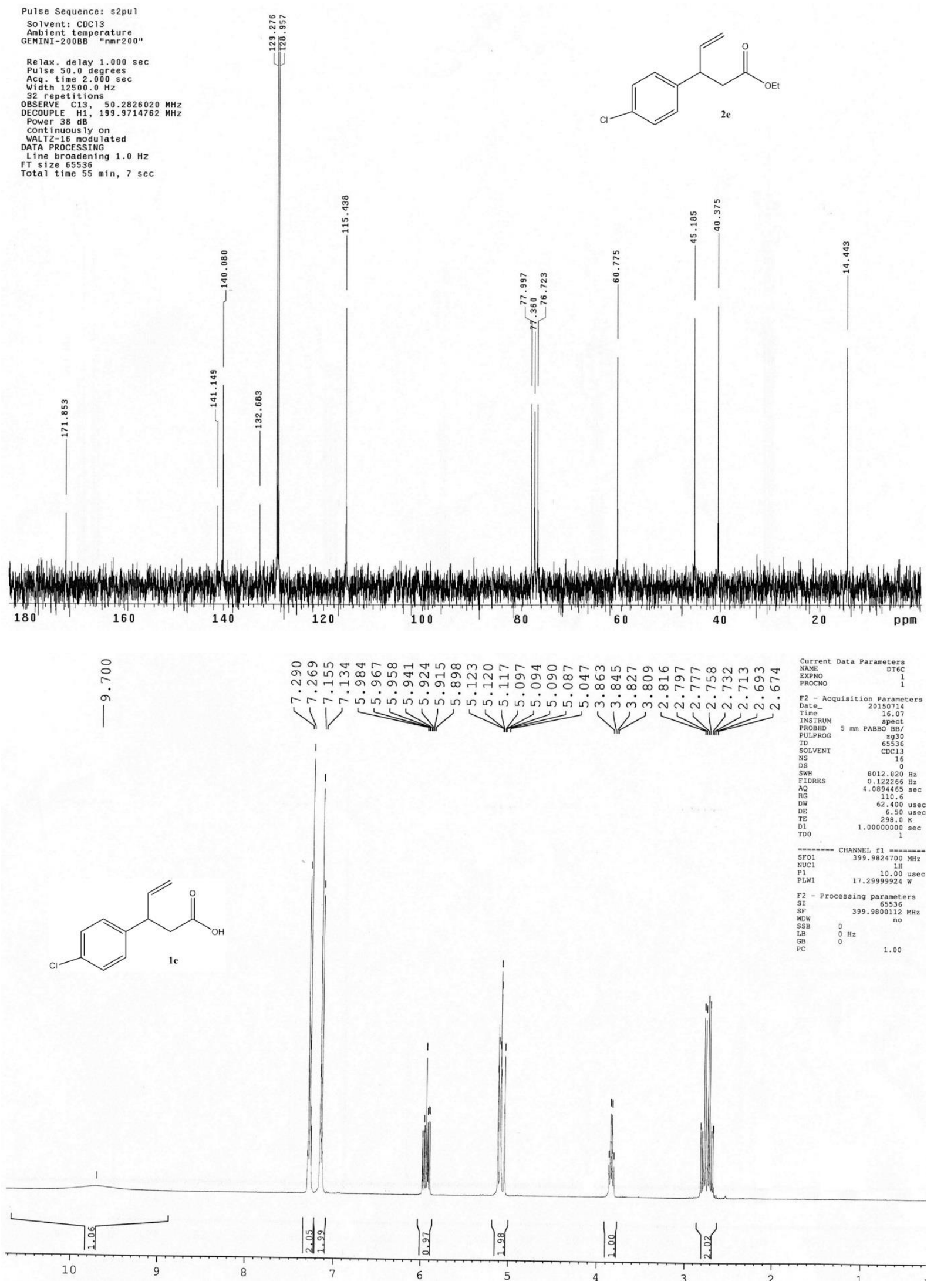




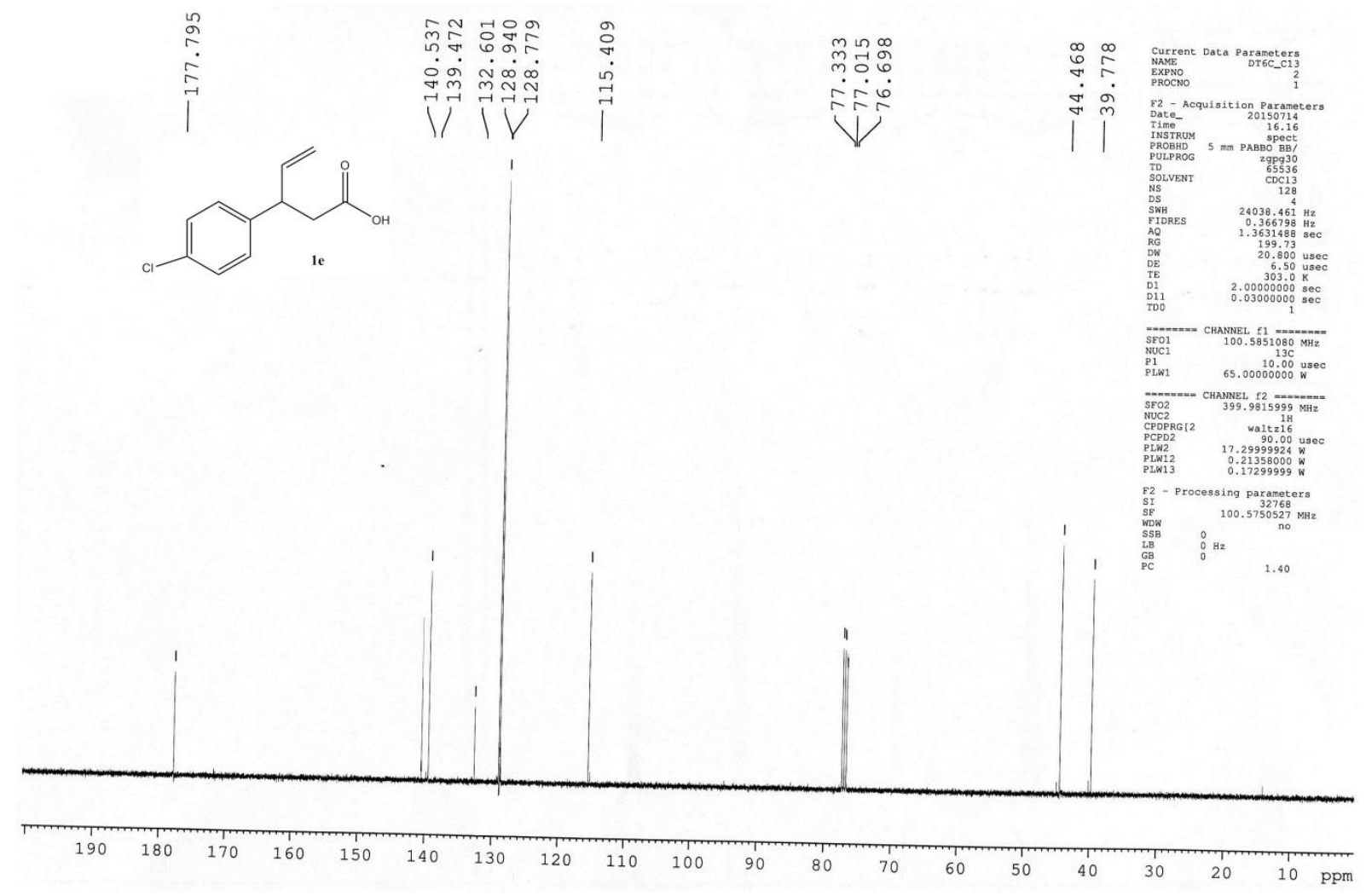

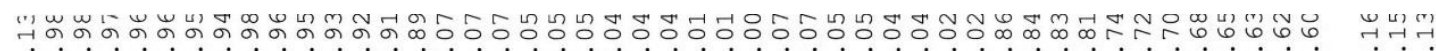

ن

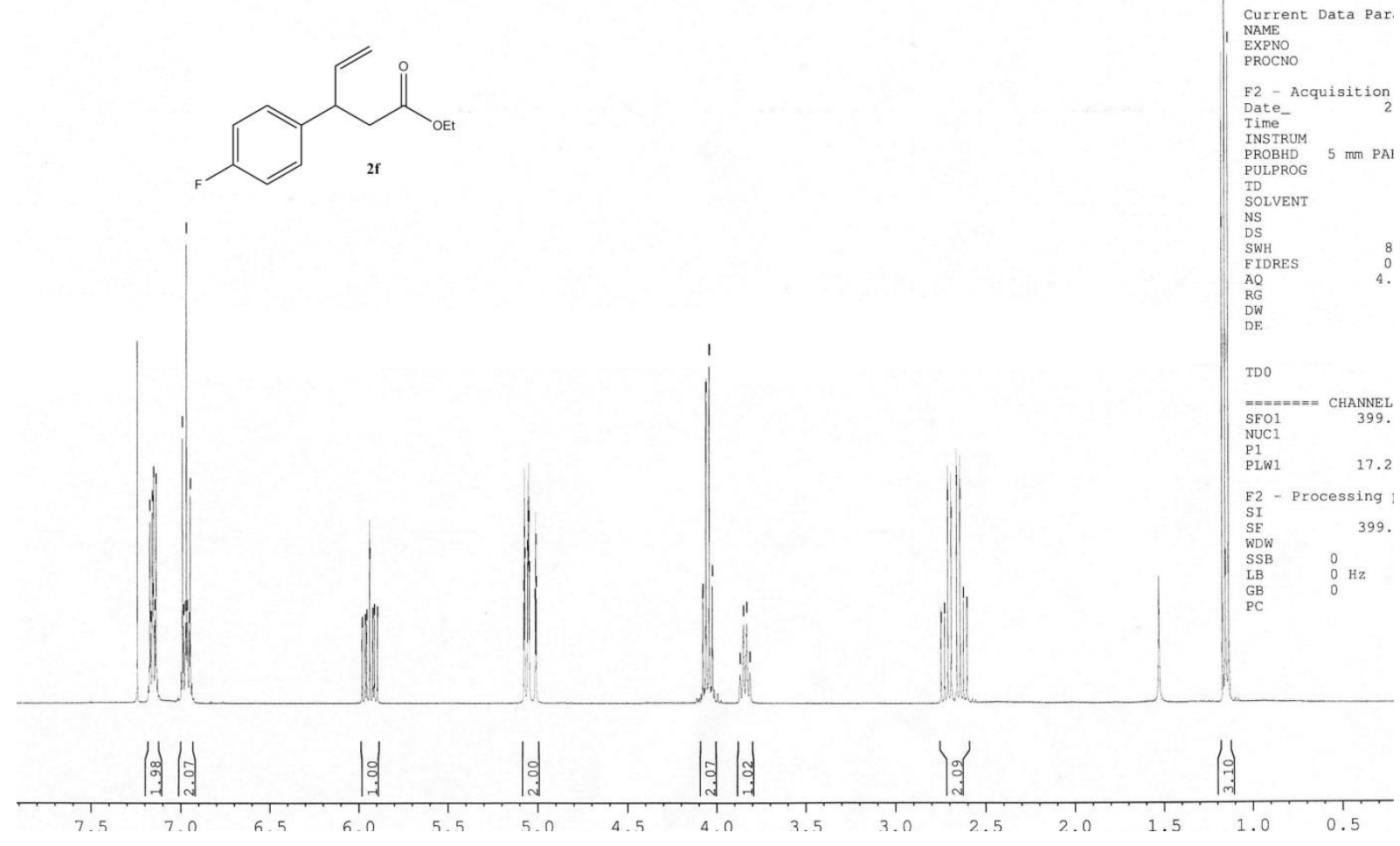



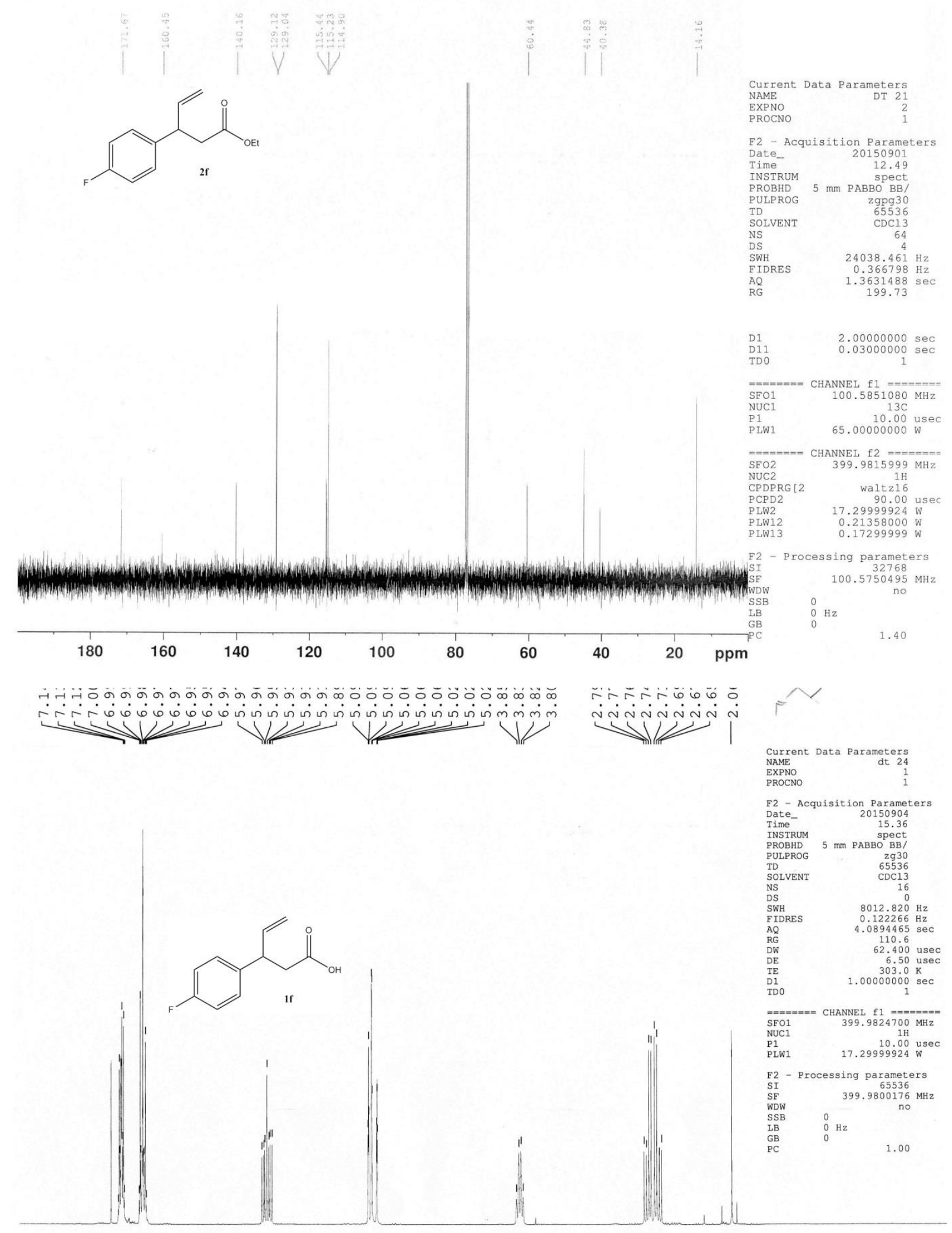

EXPNO
PROCNO

F2 - Acquisition Parameters
Date_

Time-

INSTRUM

spect
PROBHD $5 \mathrm{~mm}$ PABBO BB/

\begin{tabular}{lr} 
PULPROG & zg30 \\
TD & 65536 \\
\hline
\end{tabular}

$\begin{array}{lr}\text { SOLVENT } & \text { CDC13 } \\ \text { NS } & 16 \\ \text { DS } & 0 \\ \text { SWH } & 8012.820\end{array}$

$\begin{array}{lr}\text { SWH } & 8012.820 \mathrm{~Hz} \\ \text { FIDRES } & 0.122266 \mathrm{~Hz} \\ & 4.0894465 \mathrm{sec}\end{array}$

$\begin{array}{lr}\text { AQ } & 4.0894465 \mathrm{sec} \\ \text { RG } & 110.6 \mathrm{use} \\ \text { DW } & 62.400 \mathrm{use}\end{array}$

$\begin{array}{rr} & 62.400 \text { use } \\ & 6.50 \text { use } \\ \mathrm{DE} & 303.0 \mathrm{~K} \\ \mathrm{TE} & 1.00000000 \mathrm{sec}\end{array}$

$\begin{array}{ll}\text { D1 } & 1.00000000 \mathrm{sec}\end{array}$

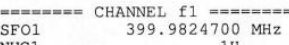

$\begin{array}{lr}\text { NUC1 } & 1 \mathrm{H} \\ \text { P1 } & 10.00 \text { usec }\end{array}$

F2 - Processing parameters

SI $\quad 65536$

SF $\quad \begin{array}{ll}399.9800176 \\ \text { WDW }\end{array}$

$\begin{array}{ll}\text { SSB } & 0 \\ \text { LB } & 0 \\ \mathrm{~Hz}\end{array}$

GB

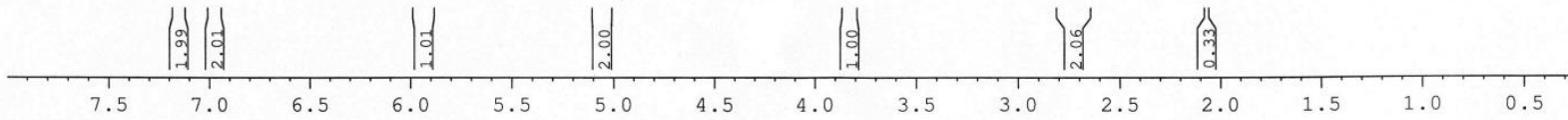




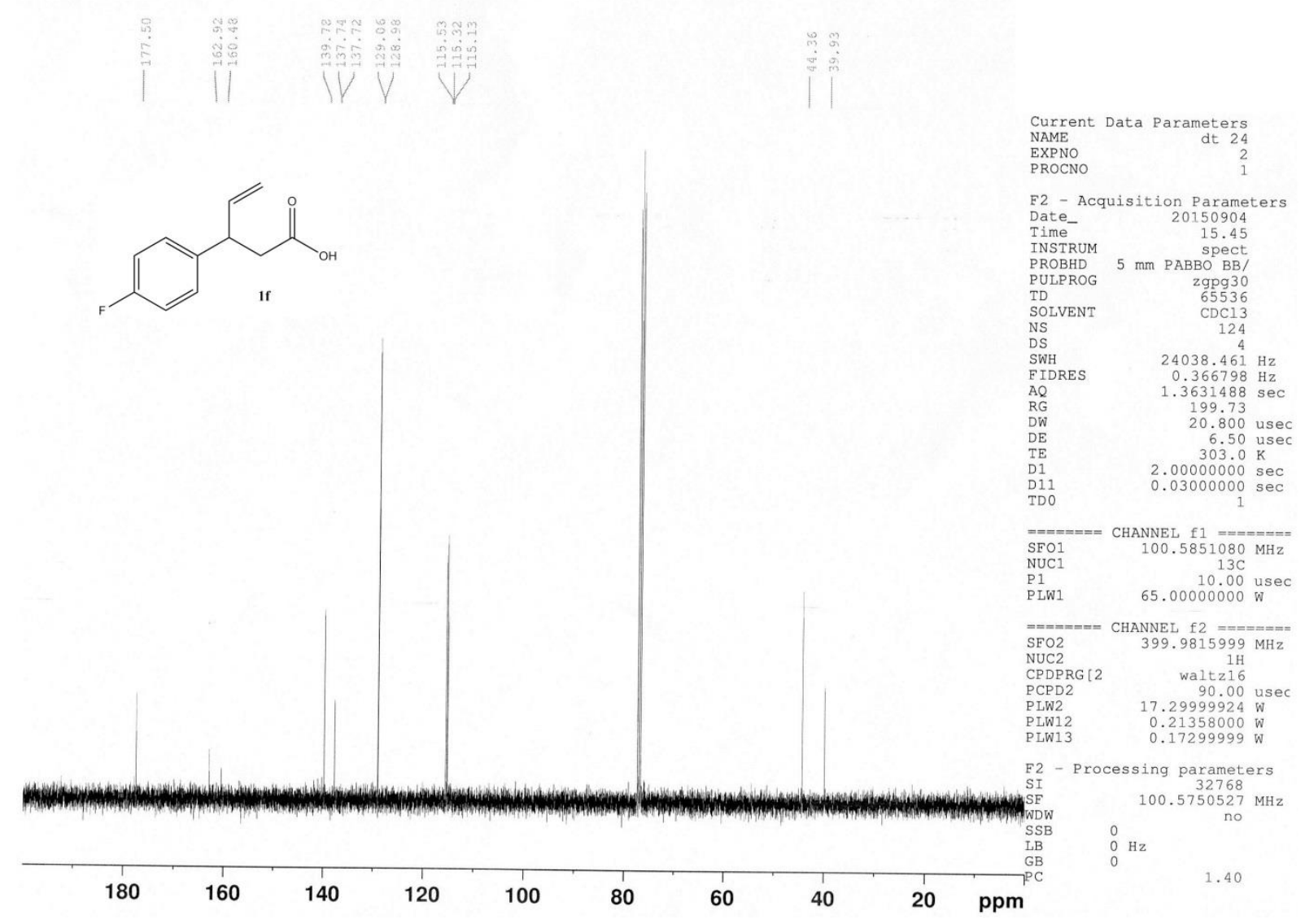

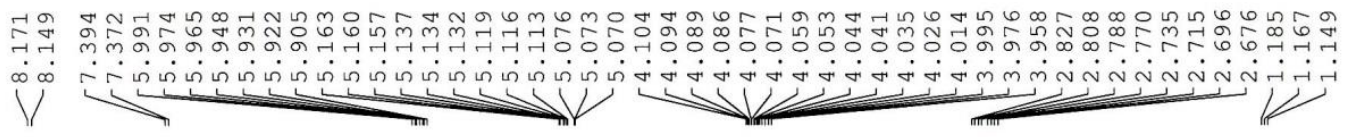

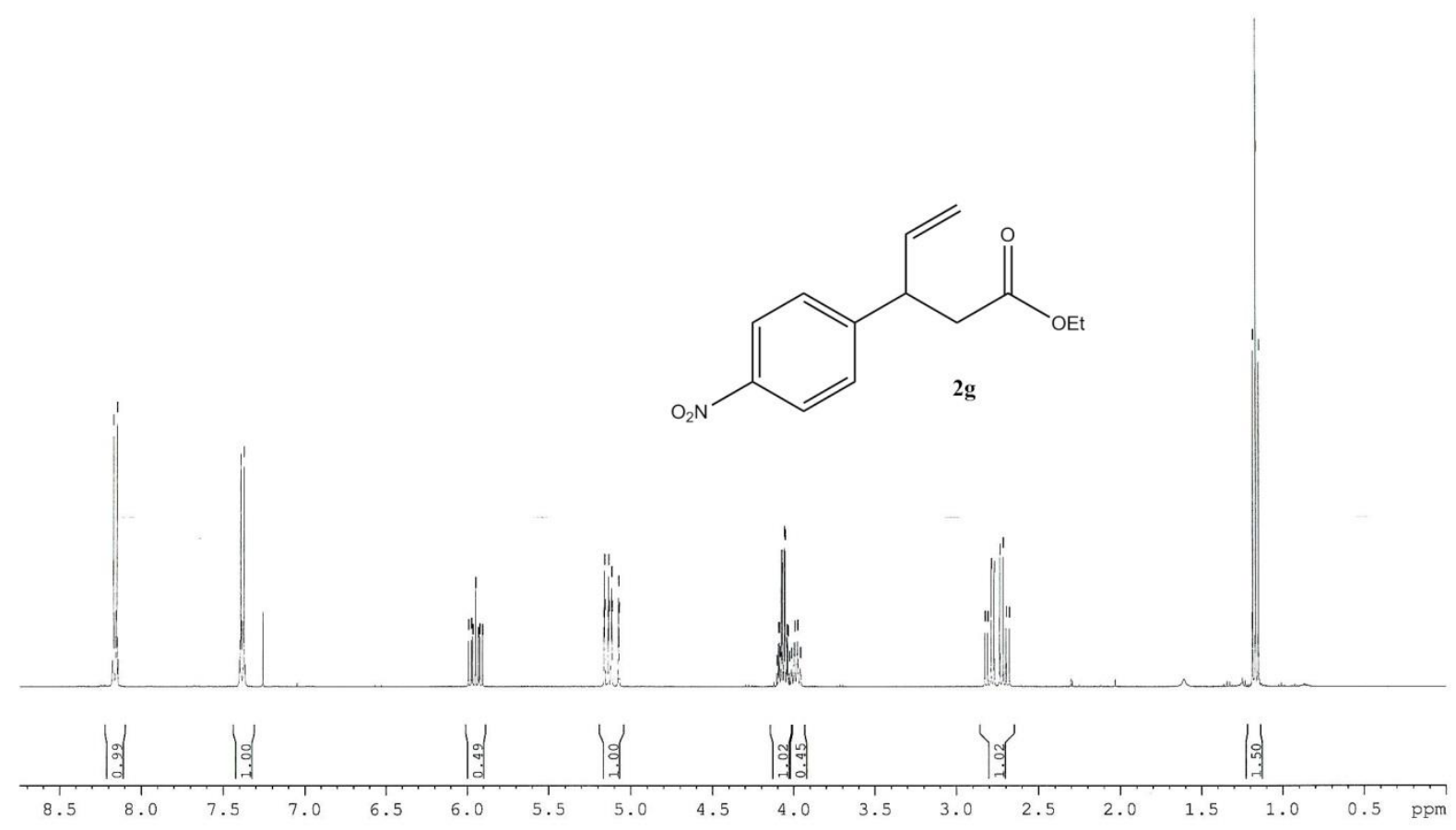



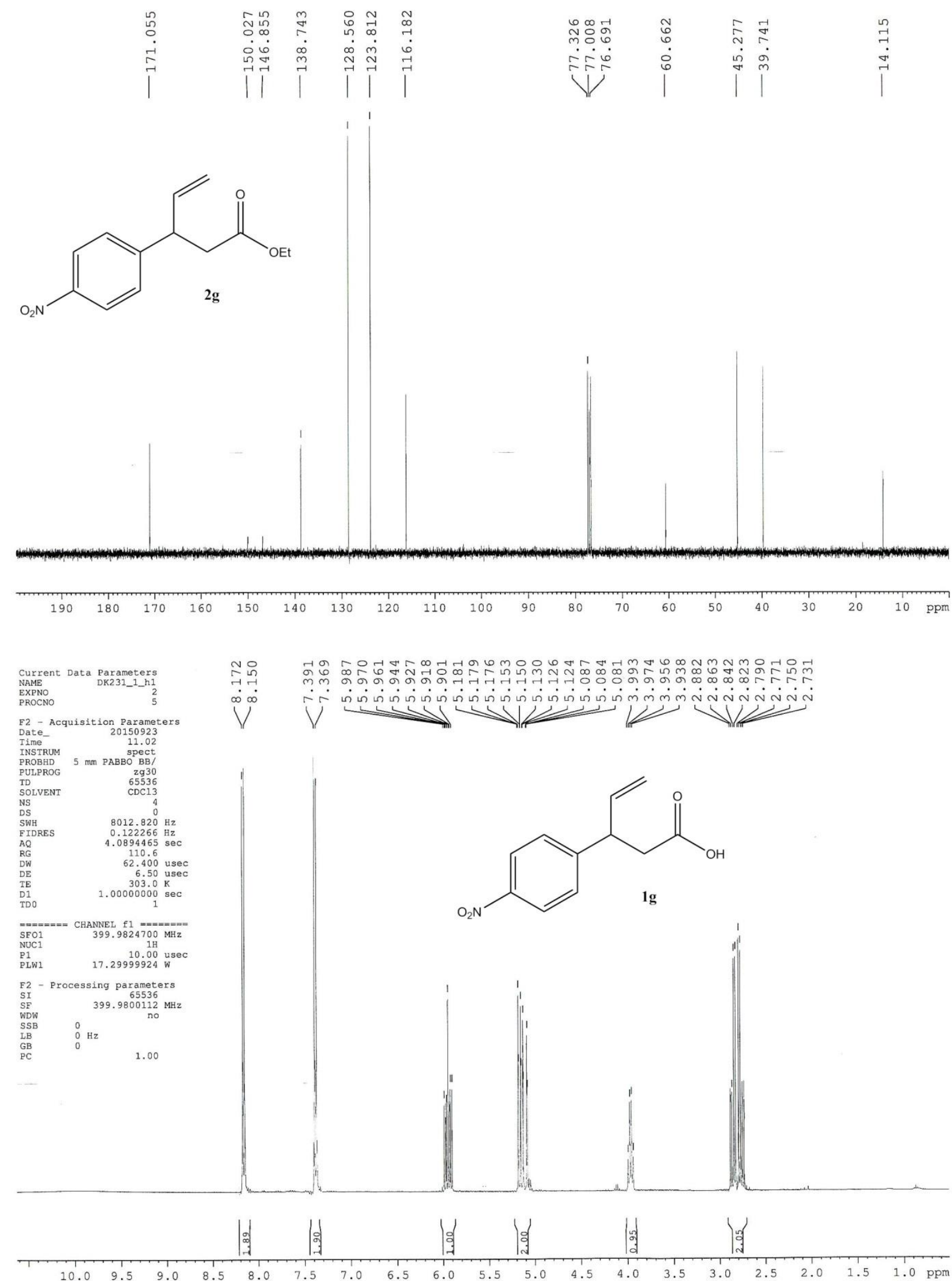

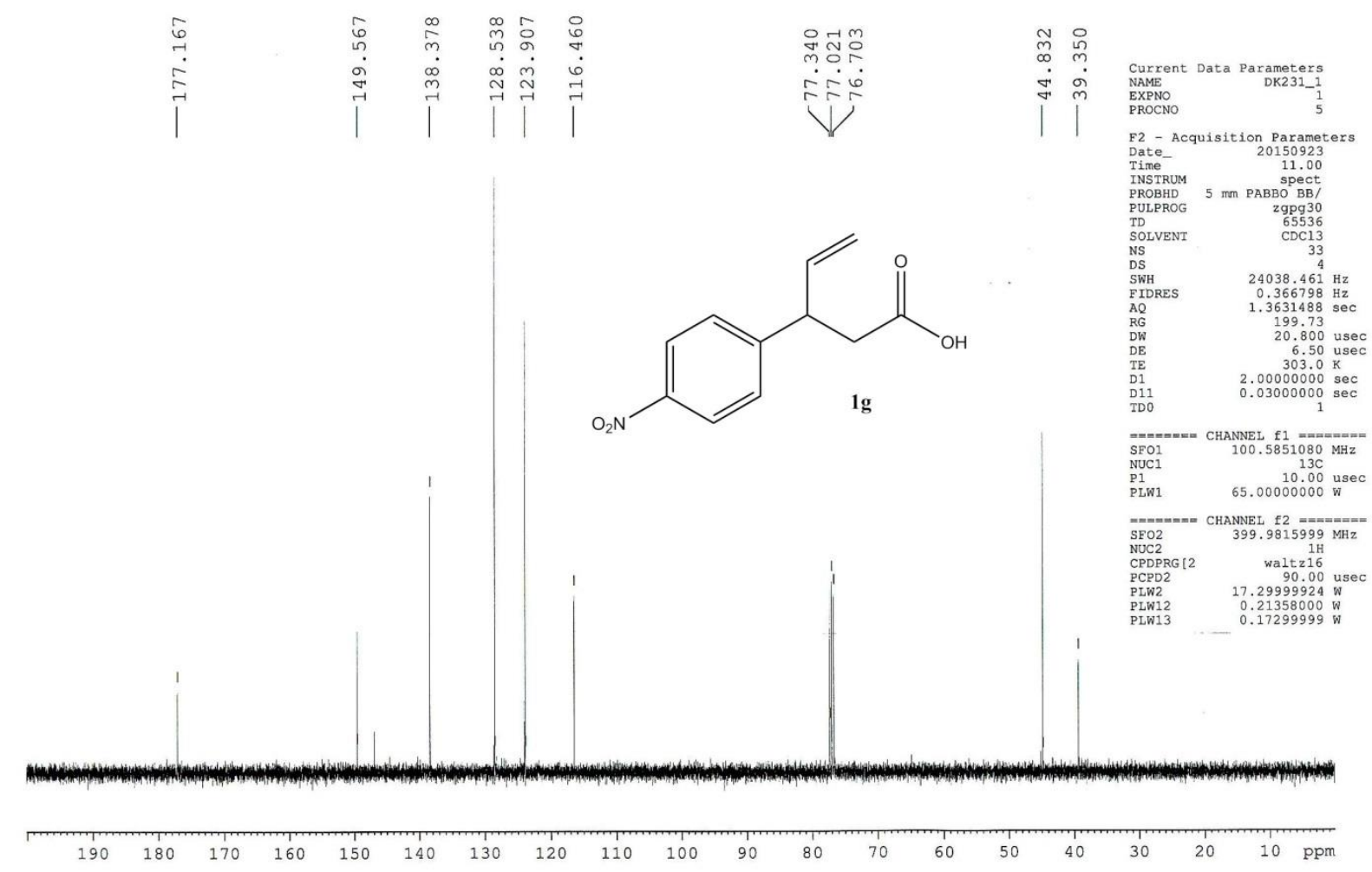

4. HPLC traces

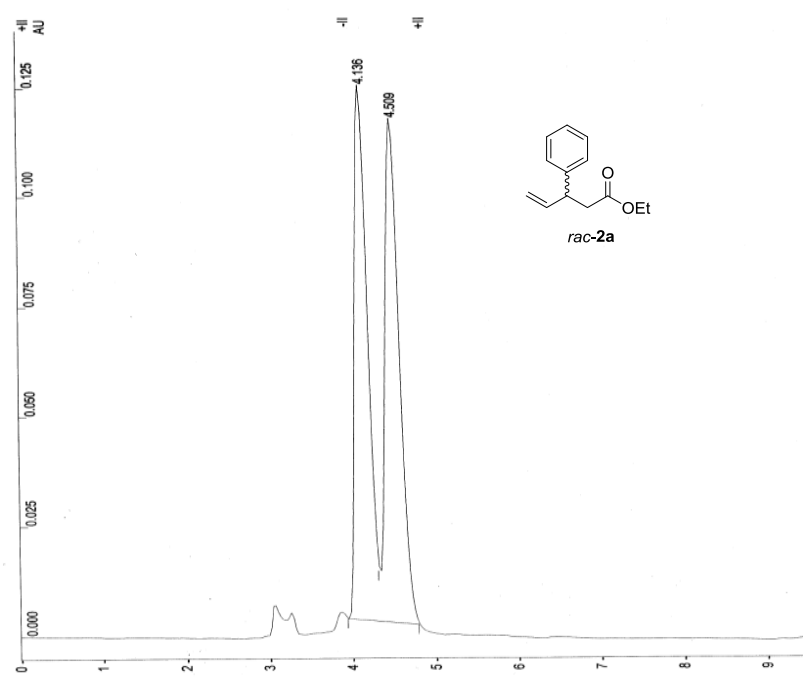



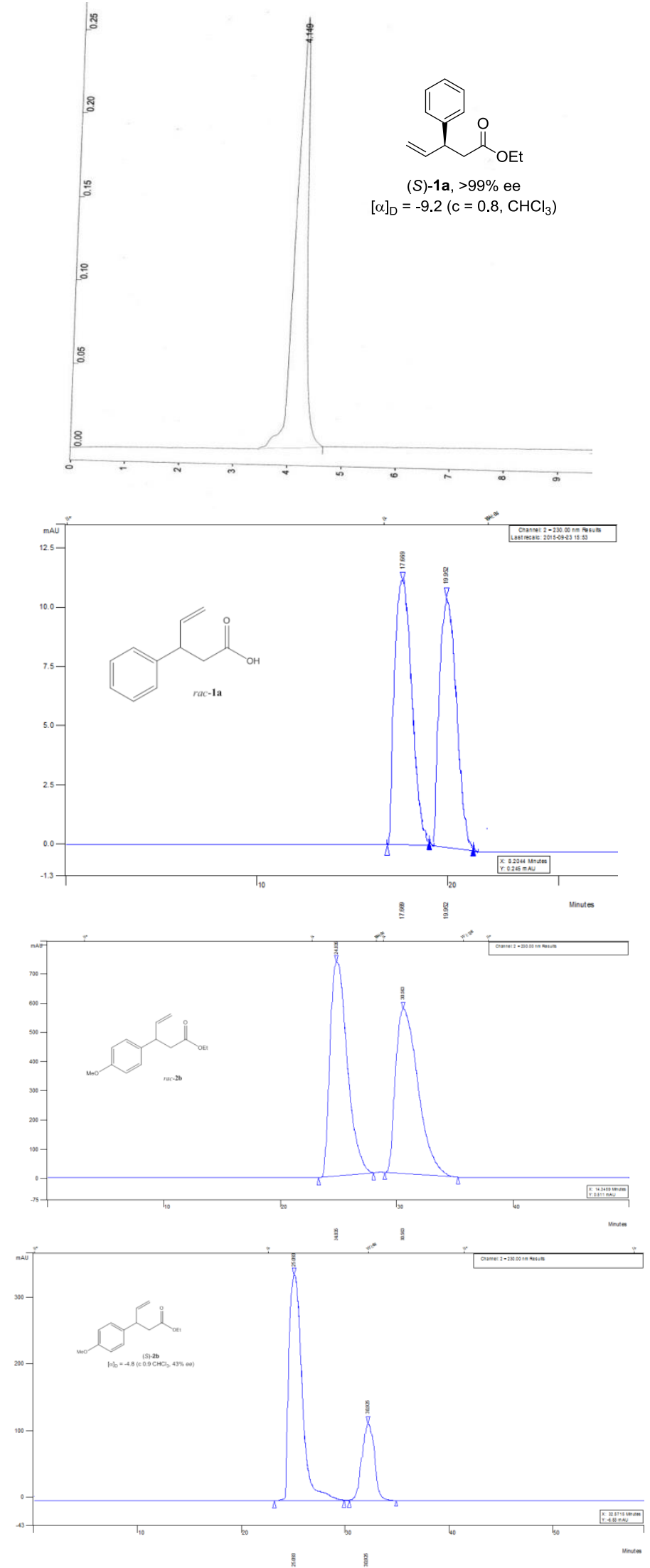

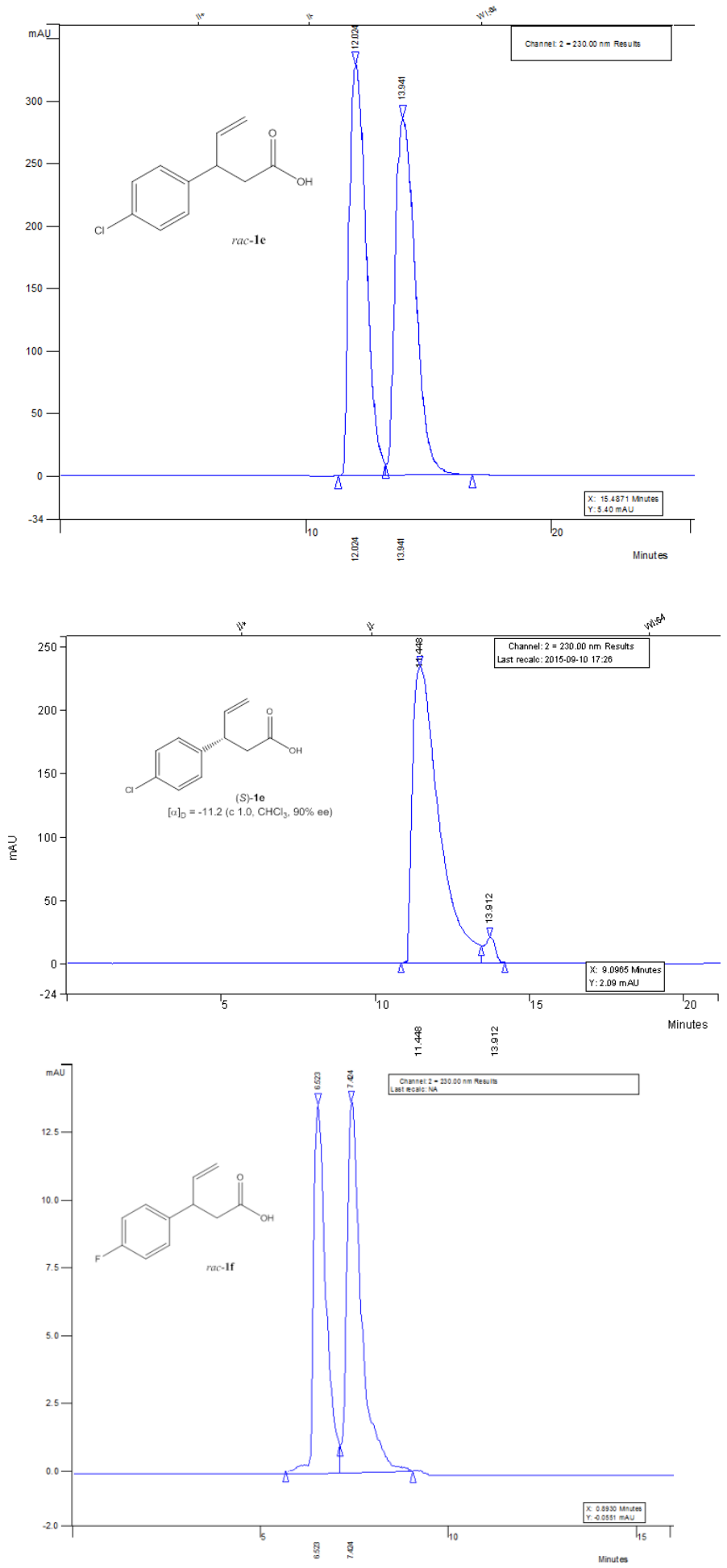

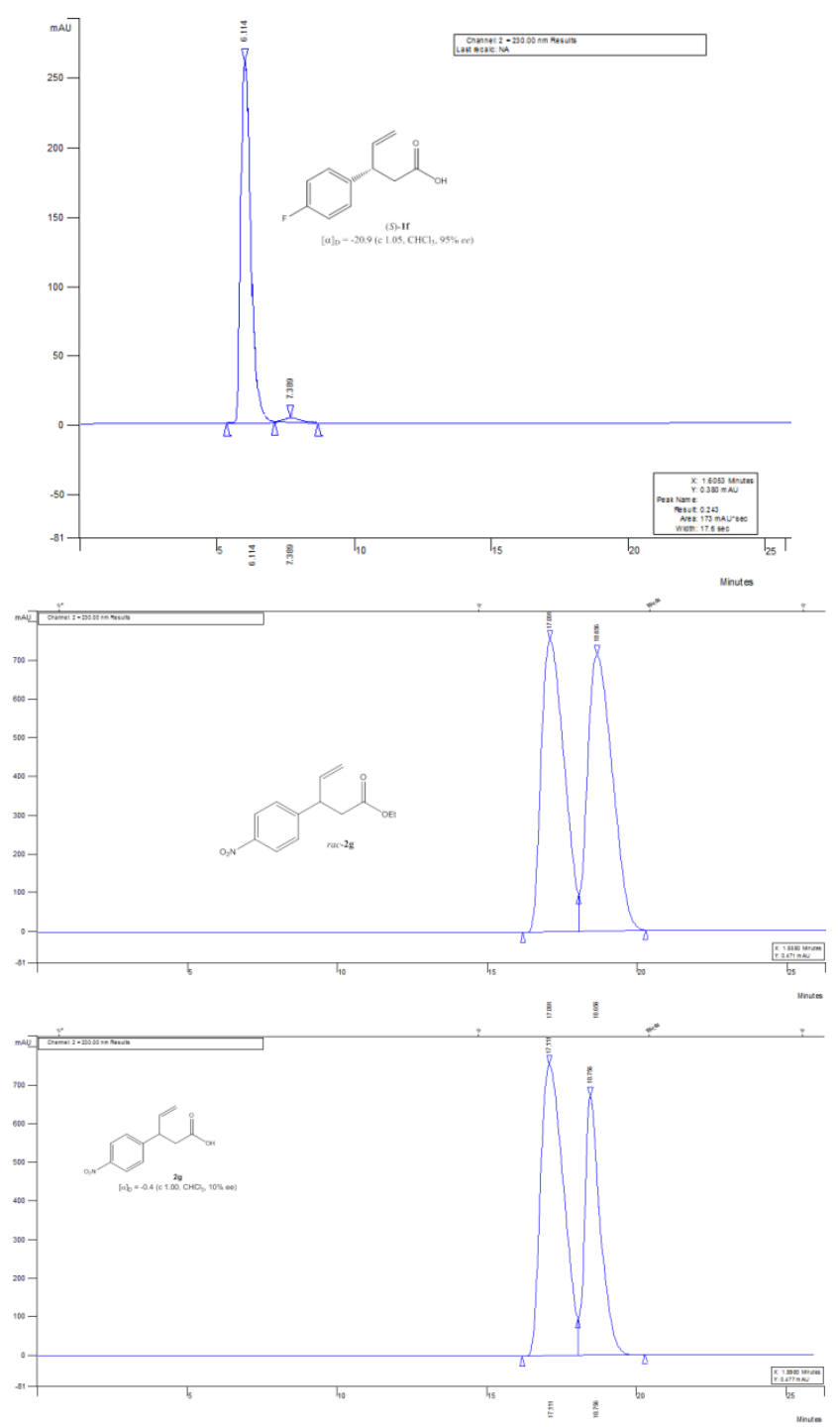

5. Photographs of rhodium complexes in $\mathrm{CDCl}_{3}$

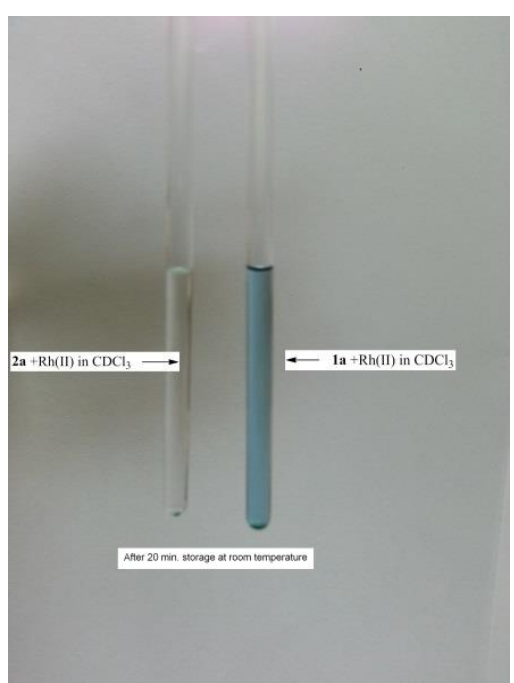

Photograph of ester $\mathbf{2} \mathbf{a}$ and acid $\mathbf{1 a}$ with rhodium(II) acetate in $\mathrm{CDCl}_{3}$ recorded after 20 minutes 


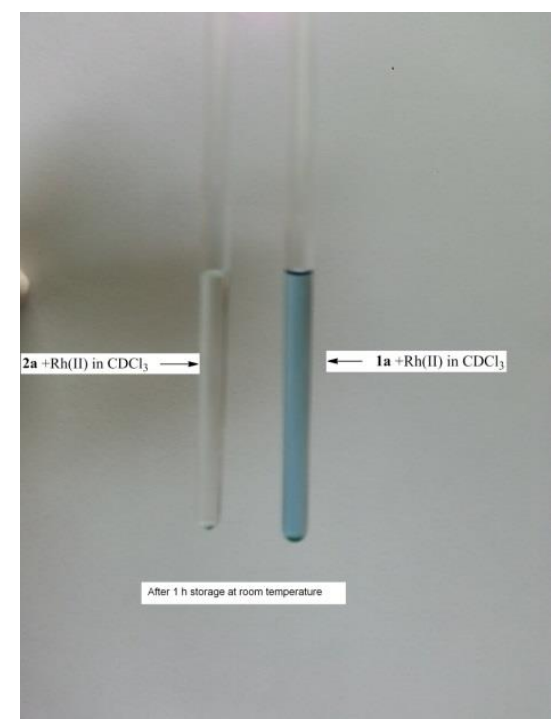

Photograph of ester $\mathbf{2 a}$ and acid $\mathbf{1 a}$ with rhodium(II) acetate in $\mathrm{CDCl}_{3}$ recorded after 1 hour

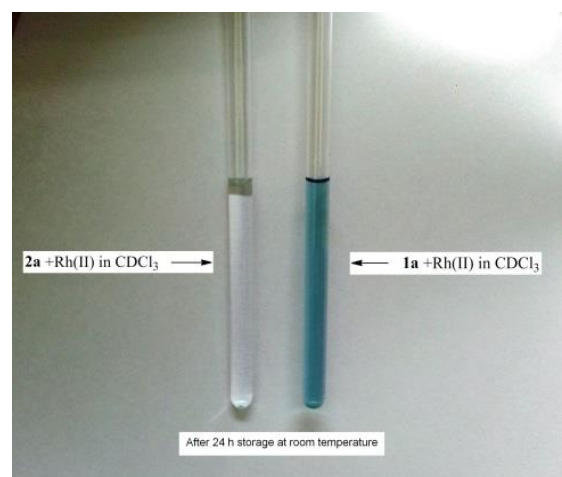

Photograph of ester $\mathbf{2 a}$ and acid $\mathbf{1 a}$ with rhodium(II) acetate in $\mathrm{CDCl}_{3}$ recorded after 24 hours

Acid (1a) without rhodium $\mathrm{C}=\mathrm{C} 1 \mathrm{HNMRregion}$

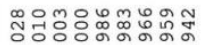

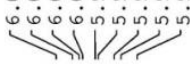

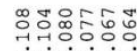

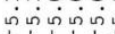

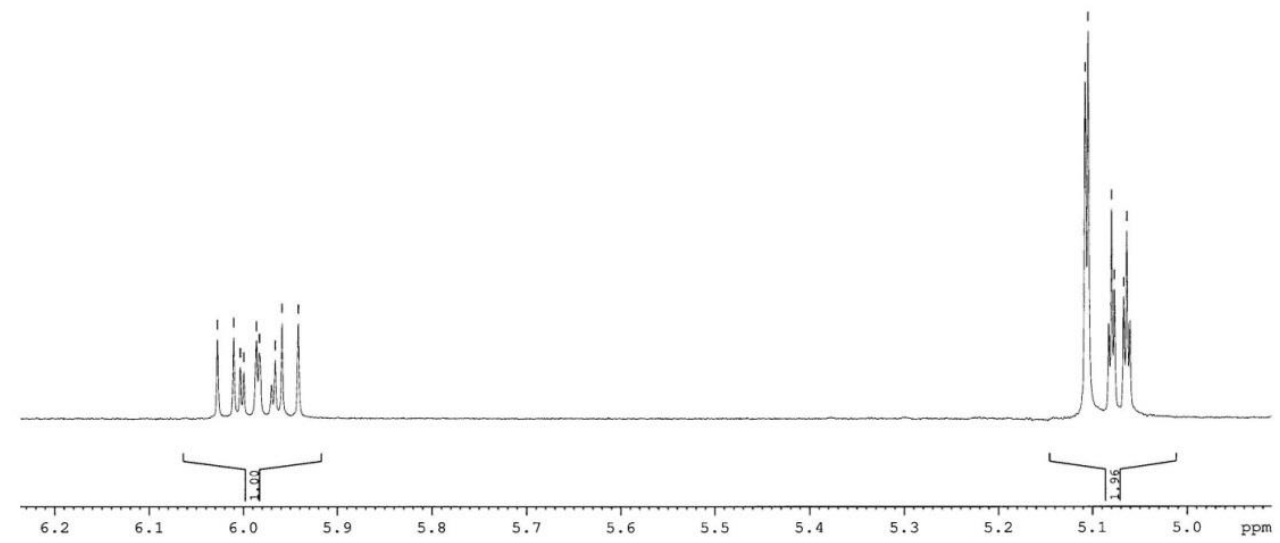




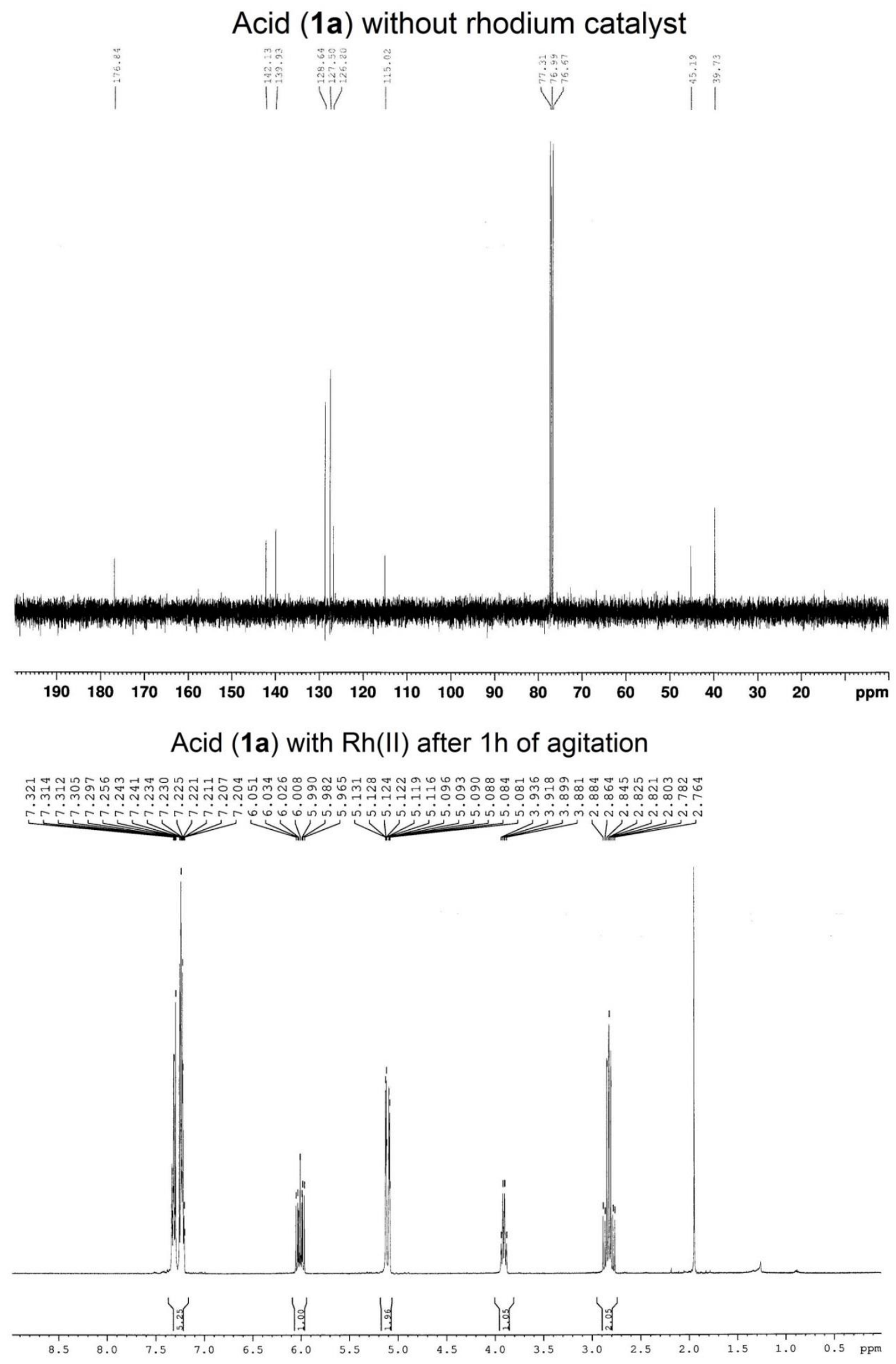


Acid (1a) with $\mathrm{Rh}(\mathrm{II})$ after $1 \mathrm{~h}$ of agitation

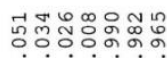

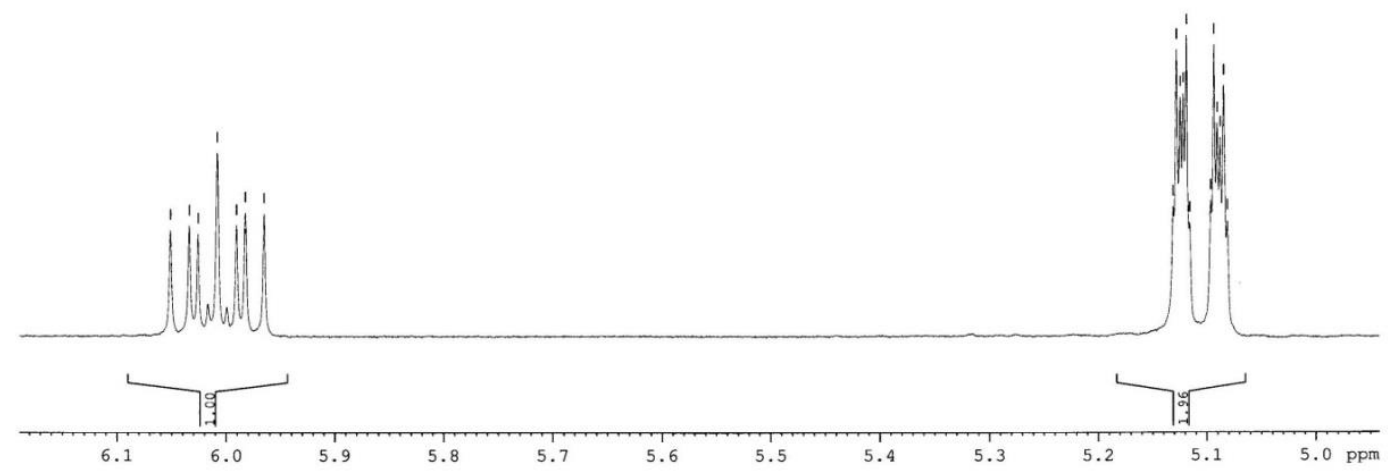

Acid (1a) with $\mathrm{Rh}(\mathrm{II})$ after $1 \mathrm{~h}$ of agitation

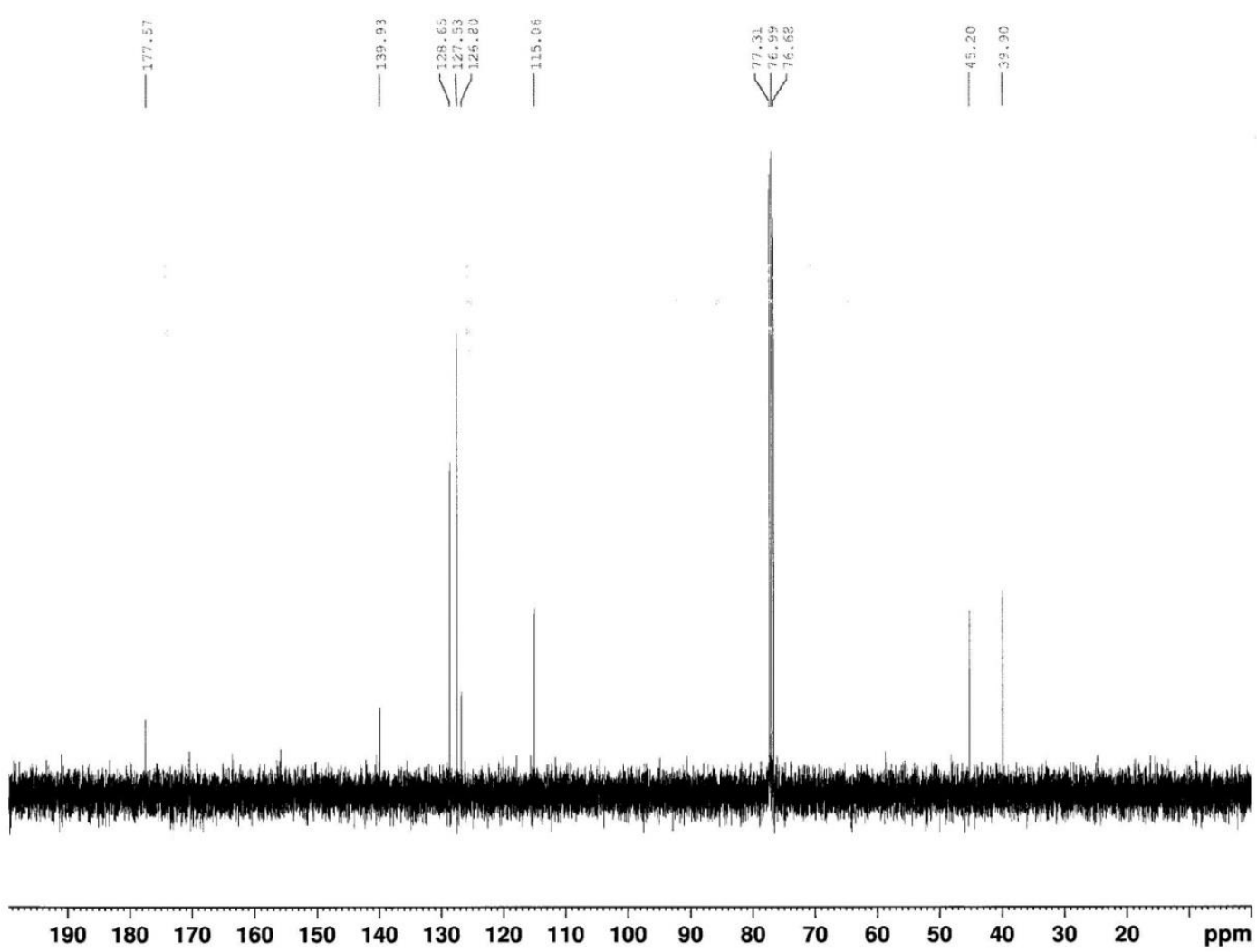


Acid (1a) with $\mathrm{Rh}(\mathrm{II})$ after 24 of agitation

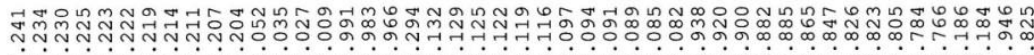

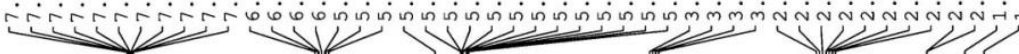
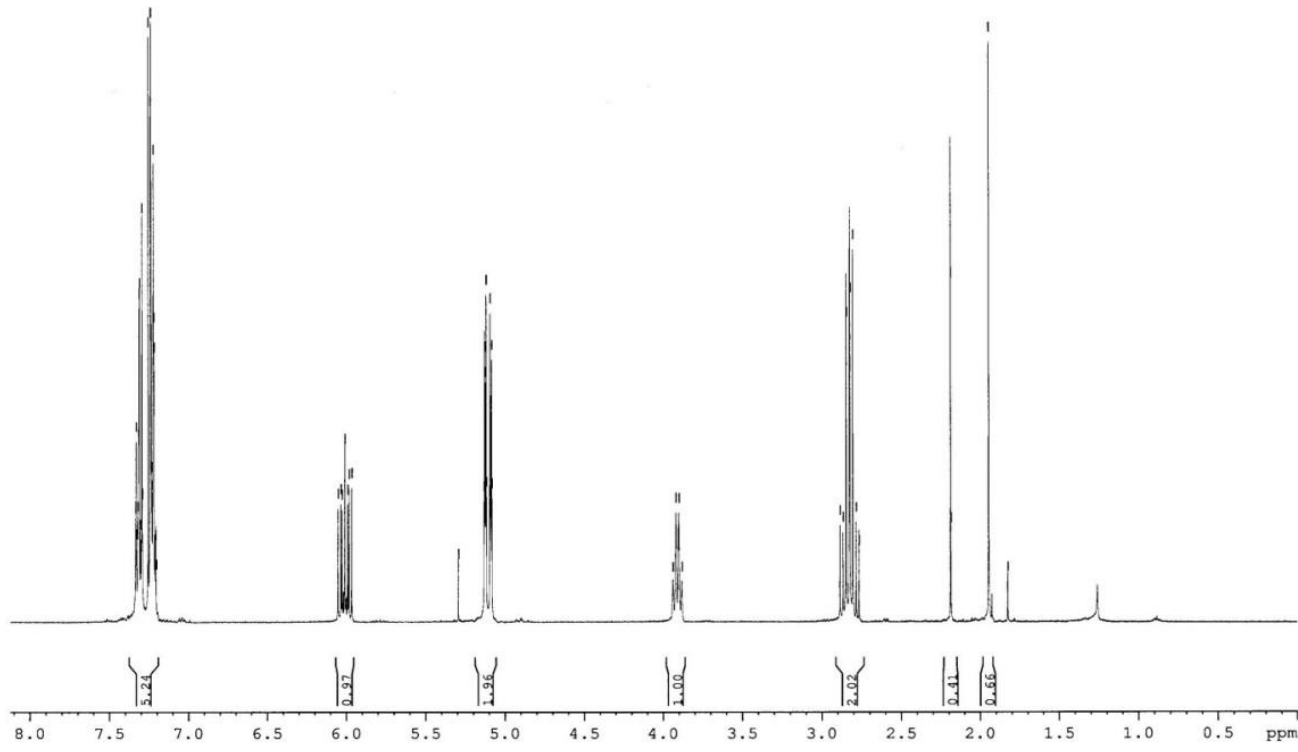

Acid (1a) with $\mathrm{Rh}(\mathrm{II})$ after 24 of agitation

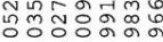

$\dot{0} \dot{0} \dot{0}$ in

$111 / 1 /$

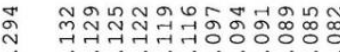

in

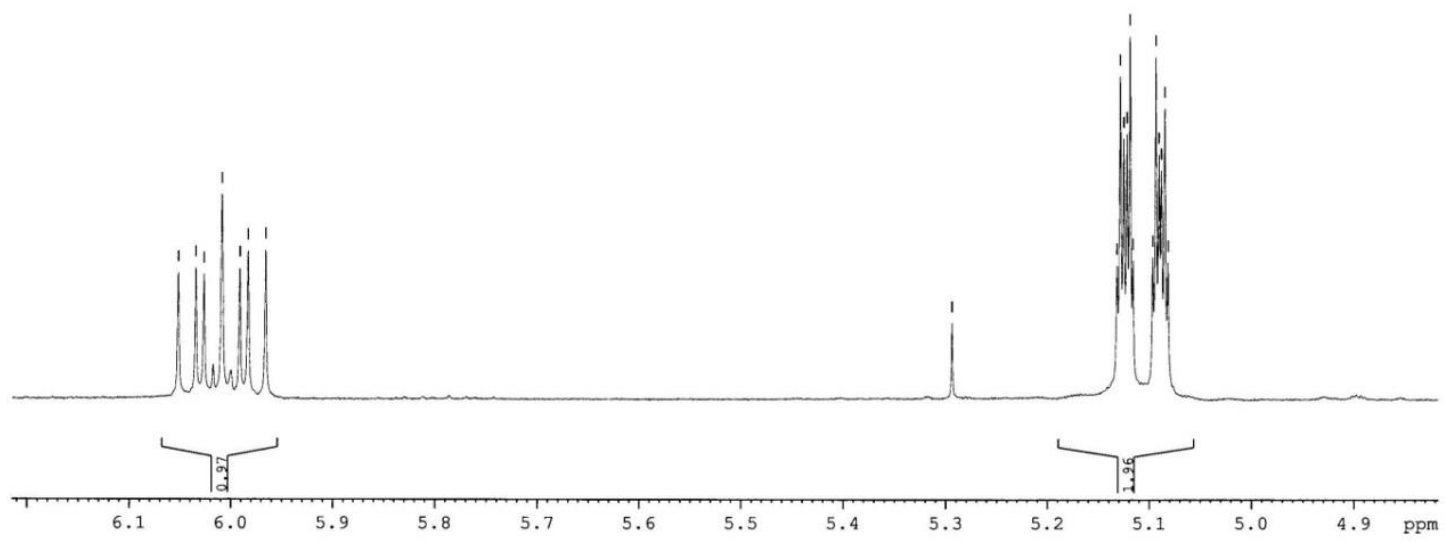




\section{Acid (1a) with $\mathrm{Rh}(\mathrm{II})$ after 24 of agitation}

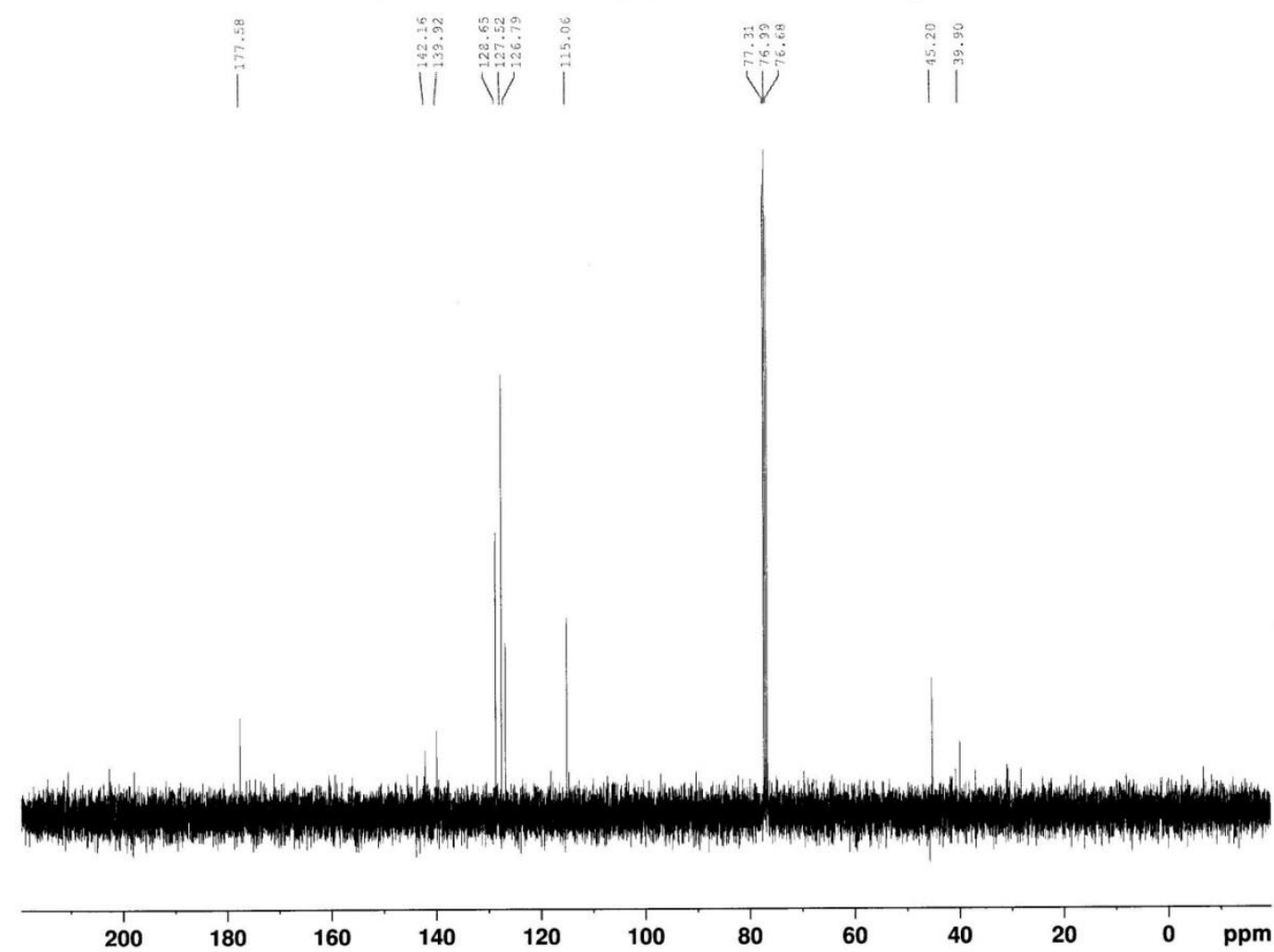

6. Isotopic exchange experiments

\section{Isotopic exchange under dynamic enzymatic kinetic resolution conditions}

To the solution of acid $1 \mathrm{a}(0.2 \mathrm{mmol})$ in toluene $(5 \mathrm{~mL})$, triethyl orthobenzoate (3 equiv.), enzyme (10 $\mathrm{mg}$ ), metal catalyst (10 mol\%) and $\mathrm{D}_{2} \mathrm{O}$ (2 equiv.) were added in $10 \mathrm{~mL}$ vial. The reaction mixture was stirring for 120 hours at $60{ }^{\circ} \mathrm{C}$. After cooling, acid 1a was purified by column chromatography (ethyl acetate/hexanes).

\section{Isotopic exchange with $\mathrm{D}_{2} \mathrm{O}$}

To the solution of acid $1 \mathrm{a}(0.2 \mathrm{mmol})$ in toluene $(5 \mathrm{~mL})$, metal catalyst $(10 \mathrm{~mol} \%)$ and $\mathrm{D}_{2} \mathrm{O}(2$ equiv.) were added in $10 \mathrm{~mL}$ vial. The reaction mixture was stirring for 120 hours at $60^{\circ} \mathrm{C}$. After cooling, acid 1a was purified by column chromatography (ethyl acetate/hexanes).

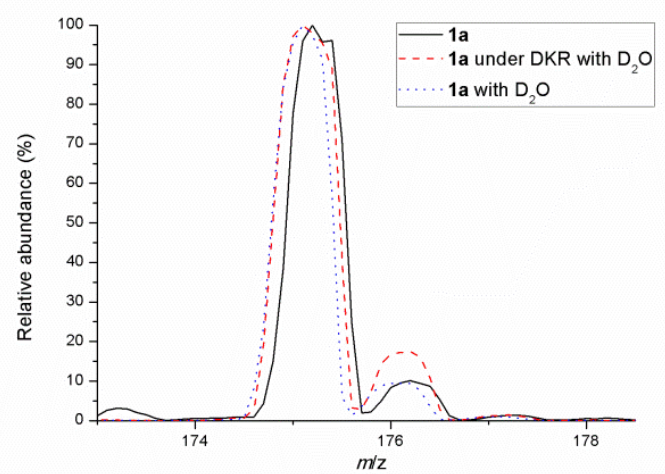

Figure S1. Isotopic pattern of acid 1a

\section{References}


1. F. Shoji, A. Masanori, S. Masatoshi, Y. Yoshihiko, Org. Lett. 2015, 17, 3822-3825.

2. A. D. Devalankar, P. U. Karabal, A. Sudalai, Org. Biomol. Chem. 2013, 11, 1280-1285.

3. C.-G. Yang, N. W. Reich, Z. Shi, C. He, Org. Lett. 2005, 7, 4553-4556.

4. A. Wzorek, B. Gawdzik, W. Gładkowski, M. Urbaniak, A. Barańska, M. Malińska, K. Woźniak, K. Kempińska, J. Wietrzyk, J. Mol. Struct. 2013, 1047, 160-168.

5. M. Gao, D.-X. Wang, Q.-Y. Zheng, M.-X. Wang, J. Org. Chem. 2006, 71, 9532-9535.

6. E. Brown, C. Deroye, J. Touet, Tetrahedron: Asymmetry 1998, 9, 1605.

7. K. Miyata, H. Kutsuna, S. Kawakami, M. Kitamura, Angew. Chem. Int. Ed. 2011, 50, 4649-4653. 